NASA/TM-2004-213204

\title{
On the Development of a Unique Arc Jet Test Apparatus for Control Surface Seal Evaluations
}

Joshua R. Finkbeiner, Patrick H. Dunlap, Jr., and Bruce M. Steinetz Glenn Research Center, Cleveland, Ohio

Malcolm Robbie, Gus Baker, and Arthur Erker Analex Corporation, Brook Park, Ohio 
Since its founding, NASA has been dedicated to the advancement of aeronautics and space science. The NASA Scientific and Technical Information (STI) Program Office plays a key part in helping NASA maintain this important role.

The NASA STI Program Office is operated by Langley Research Center, the Lead Center for NASA's scientific and technical information. The NASA STI Program Office provides access to the NASA STI Database, the largest collection of aeronautical and space science STI in the world. The Program Office is also NASA's institutional mechanism for disseminating the results of its research and development activities. These results are published by NASA in the NASA STI Report Series, which includes the following report types:

- TECHNICAL PUBLICATION. Reports of completed research or a major significant phase of research that present the results of NASA programs and include extensive data or theoretical analysis. Includes compilations of significant scientific and technical data and information deemed to be of continuing reference value. NASA's counterpart of peerreviewed formal professional papers but has less stringent limitations on manuscript length and extent of graphic presentations.

- TECHNICAL MEMORANDUM. Scientific and technical findings that are preliminary or of specialized interest, e.g., quick release reports, working papers, and bibliographies that contain minimal annotation. Does not contain extensive analysis.

- CONTRACTOR REPORT. Scientific and technical findings by NASA-sponsored contractors and grantees.
- CONFERENCE PUBLICATION. Collected papers from scientific and technical conferences, symposia, seminars, or other meetings sponsored or cosponsored by NASA.

- SPECIAL PUBLICATION. Scientific, technical, or historical information from NASA programs, projects, and missions, often concerned with subjects having substantial public interest.

- TECHNICAL TRANSLATION. Englishlanguage translations of foreign scientific and technical material pertinent to NASA's mission.

Specialized services that complement the STI Program Office's diverse offerings include creating custom thesauri, building customized databases, organizing and publishing research results ... even providing videos.

For more information about the NASA STI Program Office, see the following:

- Access the NASA STI Program Home Page at http://www.sti.nasa.gov

- E-mail your question via the Internet to help@sti.nasa.gov

- Fax your question to the NASA Access Help Desk at 301-621-0134

- Telephone the NASA Access Help Desk at 301-621-0390

- Write to:

NASA Access Help Desk

NASA Center for AeroSpace Information 7121 Standard Drive

Hanover, MD 21076 
NASA/TM-2004-213204

AIAA-2004-3891

\section{On the Development of a Unique Arc Jet Test Apparatus for Control Surface Seal Evaluations}

Joshua R. Finkbeiner, Patrick H. Dunlap, Jr., and Bruce M. Steinetz

Glenn Research Center, Cleveland, Ohio

Malcolm Robbie, Gus Baker, and Arthur Erker

Analex Corporation, Brook Park, Ohio

Prepared for the

40th Joint Propulsion Conference and Exhibit

cosponsored by the AIAA, ASME, SAE, and ASEE

Fort Lauderdale, Florida, July 11-14, 2004

National Aeronautics and

Space Administration

Glenn Research Center 


\section{Acknowledgments}

The authors would like to thank Stan Bouslog for performing arc jet flow and thermal calculations and Ron Lewis and Jim Milhoan, NASA Johnson Space Center, for their support in the design of this test fixture.

Trade names or manufacturers' names are used in this report for identification only. This usage does not constitute an official endorsement, either expressed or implied, by the National Aeronautics and Space Administration.

Available from

NASA Center for Aerospace Information 7121 Standard Drive

Hanover, MD 21076
National Technical Information Service 5285 Port Royal Road Springfield, VA 22100 


\title{
On the Development of a Unique Arc Jet Test Apparatus for Control Surface Seal Evaluations
}

\author{
Joshua R. Finkbeiner, Patrick H. Dunlap, Jr., and Bruce M. Steinetz \\ National Aeronautics and Space Administration \\ Glenn Research Center \\ Cleveland, Ohio 44135 \\ Malcolm Robbie, Gus Baker, and Arthur Erker \\ Analex Corporation \\ Brook Park, Ohio 44142
}

\begin{abstract}
NASA GRC has developed a unique test apparatus capable of evaluating control surface seal and flap designs under simulated reentry heating conditions in NASA JSC's arc jet test facility. The test apparatus is capable of testing a variety of seal designs with a variety of control surface materials and designs using modular components. The flap angle can be varied during testing, allowing modification of the seal environment while testing is in progress. The flap angle is varied using an innovative transmission system which limits heat transfer from the hot flap structure to the motor, all while keeping the components properly aligned regardless of thermal expansion. A combination of active and passive cooling is employed to prevent thermal damage to the test fixture while still obtaining the target seal temperature.
\end{abstract}

\section{Introduction}

$\mathrm{F}$ uture reentry vehicles will require advanced control surface seals to protect underlying structures from the intense heating environment of reentry into the Earth's atmosphere. Representative control surface seal locations on an example reentry vehicle (X-38 Crew Return Vehicle) are shown in Fig. 1. NASA's Glenn Research Center (GRC) is currently developing advanced control surface seals to meet these needs. Using state-of-the-art test facilities, new seal concepts are evaluated using high temperature compression tests, high temperature scrubbing tests, and room temperature flow tests. ${ }^{1}$ While these test rigs provide valuable information about seal performance, they cannot fully simulate the extreme reentry heating environment, including the combination of heat flux, temperature, pressure drop, wear damage, and material compatibility. The current paper discusses the development of a new test fixture to assess advanced seal concepts in simulated reentry heating conditions. This test fixture will permit testing of a variety of seal sizes, shapes, and materials against a wide range of candidate advanced control surface designs and materials at near-operating temperatures and pressure drops.

\section{A. Seals and Seal Requirements}

Seals on the current shuttle orbiters are recessed from the outer mold line to insulate them from the high heating rates and to keep seal temperatures below $1500^{\circ} \mathrm{F}(1100 \mathrm{~K})$. However, future vehicles are allocating less space for seals, thereby pushing them closer to the outer mold line and ultimately increasing their operating temperature. Previous studies have predicted seal temperatures greater than $2000^{\circ} \mathrm{F}(1400 \mathrm{~K})^{2}$ in next-generation reentry vehicles. In addition, future vehicles are expected to utilize hot ceramic-matrix composite (CMC) structures rather than the highly insulating tile system used on the shuttle orbiters. The combination of higher thermal conductivity of the CMC materials, proximity of the seals to the outer mold line, heat convection to the seals, and an inability to radiate heat from the seal gaps results in higher seal temperatures.

Table 1 lists several requirements for a successful seal design in the presence of the extreme reentry environment. Depending on vehicle application, the seal must survive temperatures between $1800^{\circ} \mathrm{F}$ and $2200^{\circ} \mathrm{F}(1300 \mathrm{~K}$ to 1500 


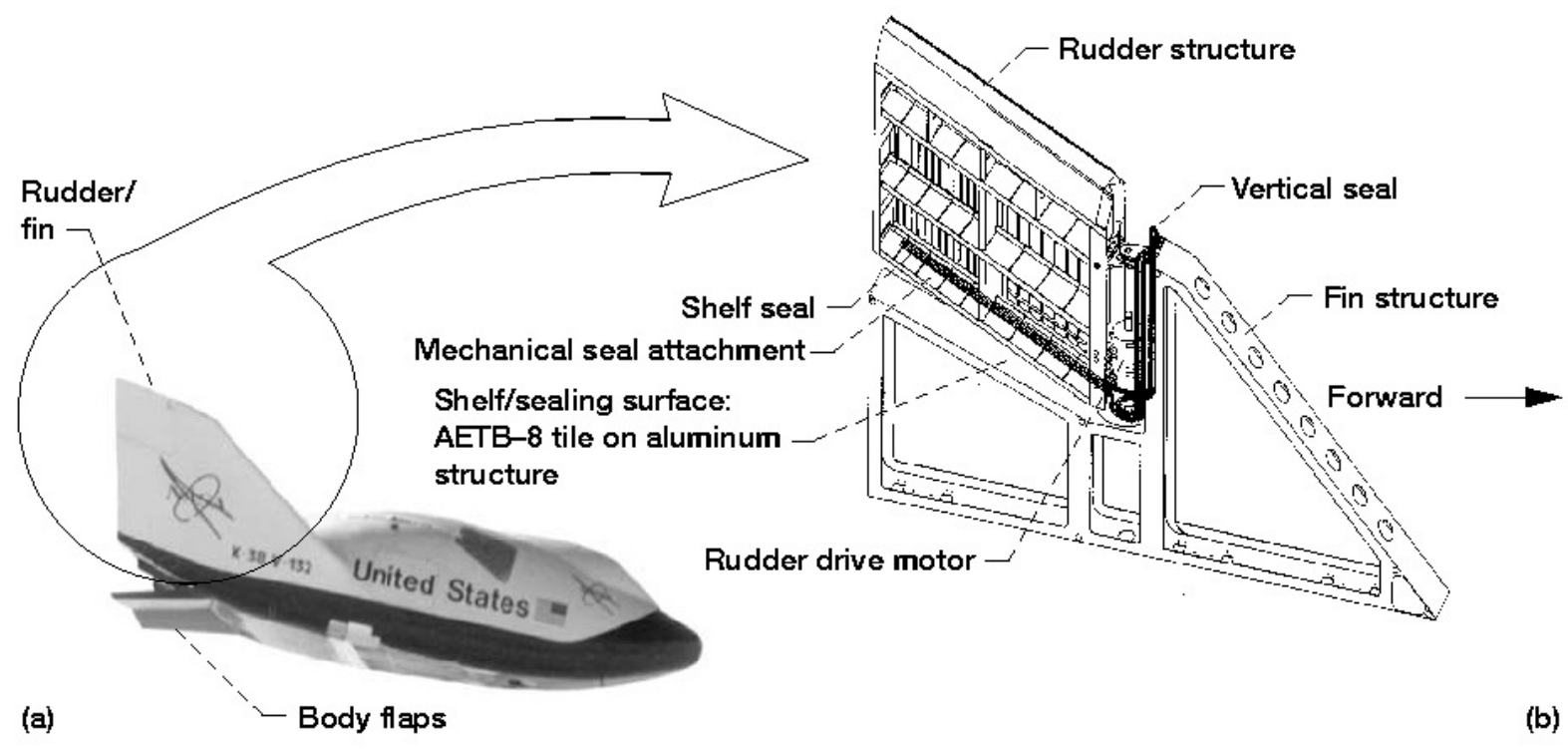

Figure 1. Vehicle showing control surface seal locations. (a) X-38 vehicle. (b) Rudder/fin structure and seal locations.

K) without active cooling and seal against a pressure drop of up to $56 \mathrm{psf}(2.6 \mathrm{kPa})$ with minimal leakage. The seal material must withstand both the oxidizing environment of reentry as well as abrasive scrubbing against rough $(\sim 515-575 \mu$ in $(\sim 13.1-14.6 \mu \mathrm{m}))$ surfaces. ${ }^{3}$ Additionally, the seal must maintain its resiliency at high temperatures to accommodate opening and closing of the seal gap due to the differences in thermal expansion between adjacent structures and actuation of the control surfaces. Furthermore, the seals should be reusable for multiple reentries, each of which lasts roughly $2200 \mathrm{sec}(37 \mathrm{~min})^{2}$

Table 1. Control surface seal design requirements

\begin{tabular}{|l|l|}
\hline Design Requirement & Goal \\
\hline \hline Seal temperature & $\begin{array}{l}\text { Between } 1800^{\circ} \mathrm{F} \text { and } 2200^{\circ} \mathrm{F}(1300 \mathrm{~K} \text { to } 1500 \mathrm{~K}), \\
\text { depending on vehicle application }\end{array}$ \\
\hline Pressure drop across seal & $56 \mathrm{psf}$ to $100 \mathrm{psf}(2.6 \mathrm{kPa}$ to $4.8 \mathrm{kPa})$ \\
\hline Leakage & Minimize \\
\hline Environmental conditions & Oxidizing environment \\
\hline Use of cooling & Operate without active cooling \\
\hline Time hot & 1000 sec to 2200 sec $(\sim 16$ min to 37 min $)$ \\
\hline Size & 0.5 in. to 1.0 in. $(1.3 \mathrm{~cm}$ to $2.5 \mathrm{~cm})$ nominal diameter \\
\hline Flexibility & $\begin{array}{l}\text { Accommodate structural non-uniformities } \\
\text { and seal around corners }\end{array}$ \\
\hline Resiliency & Accommodate seal gap openings and closings \\
\hline Seal gap size & Nominally 0.25 in. $(0.64 \mathrm{~cm})$ \\
\hline Sliding speed & Up to 8 in./sec $(20 \mathrm{~cm} / \mathrm{sec})$ \\
\hline Wear resistance & Withstand scrubbing against rough surfaces \\
\hline
\end{tabular}

Several seal design concepts have been proposed to meet the above requirements. The current state-of-the-art (SOA) control surface seal design used in the space shuttle orbiter consists of an Inconel X-750 spring tube filled with Saffil batting, all of which is overbraided with two layers of Nextel 312 ceramic sleeving. These seals have been shown to lose resiliency at the high temperatures predicted for future vehicle reentries. ${ }^{2}$ 
Several improved concepts for future reentry vehicle control surface seals are being evaluated. Improved versions of the SOA seal are currently in development and have more resilient spring tubes and engineered cores ${ }^{4}$ to better resist high temperature environments. Other seal designs place the spring preload device behind the seal (instead of within the seal), lowering the temperature to which the preload device is exposed and thereby improving resiliency. There is also interest in testing double-bulb arrangements of various rope seals, where two or more seals are stacked together to form a better overall seal. Ceramic wafer seals are also being considered for control surface seal applications because they have been shown to have leakage rates roughly an order of magnitude less than rope seals and are better suited to survive severe scrubbing damage caused by the rough surfaces of some candidate ceramic control surface materials. ${ }^{5}$

\section{B. Overview of Arc Jet Facility}

Arc jet facilities produce jets with gas enthalpies comparable to those encountered during atmospheric reentry. These facilities are used to evaluate components of a reentry vehicle's thermal protection system (TPS) and to better understand the heating and flow conditions encountered during reentry. While individual performance characteristics of seals can be evaluated using subscale laboratory experiments, an arc jet facility is ideal for testing several seal characteristics simultaneously while simulating the heat loads and time scales typical of reentry. An arc jet test facility using a welldesigned test fixture provides a very accurate recreation of the reentry environment.

In the late 1990s, GRC worked with Boeing to develop a seal arc jet test fixture for use in the 20MW Panel Test Facility at NASA Ames Research Center. ${ }^{6}$ This test fixture was designed to mate with the semi-elliptical nozzle in this facility so that high temperature exhaust flow passed out of the nozzle and over the top of the test fixture. GRC has since decided to perform a series of seal tests in the conical nozzle arc jet test facility at NASA Johnson Space Center

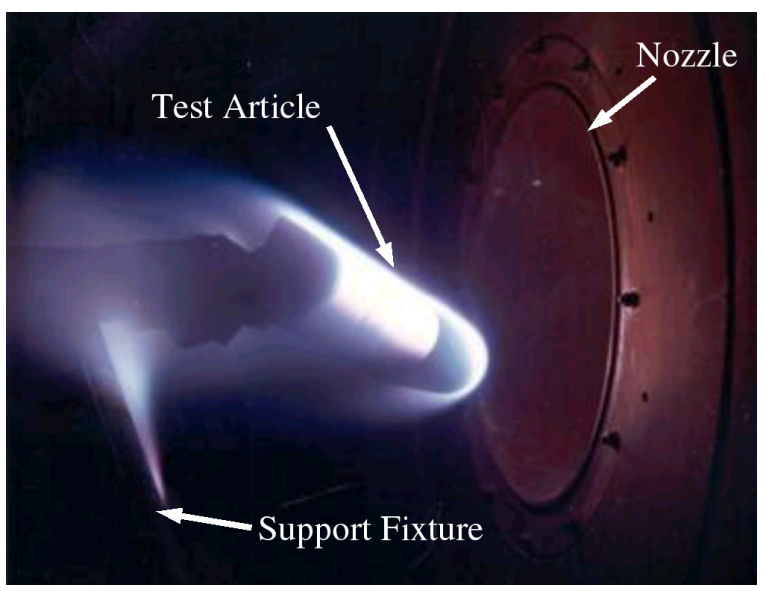

Figure 2. Photo of JSC arc jet testing using conical nozzle. (Courtesy of Johnson Space Center)

(JSC). This facility is geometrically and thermodynamically different than the facility at Ames and requires a new test fixture to account for these differences. Whereas the Ames fixture mounted flush against the nozzle and exposed only the top surface to the hot flow, the JSC facility uses a conical nozzle with the test fixture mounted several inches from the nozzle. This arrangement exposes the majority of the fixture surface area to the hot gas flow. A summary of the capabilities of the JSC conical nozzle arc jet facility is shown in Table 2 and a photograph of a representative test in the JSC arc jet facility is shown in Fig. 2.

Table 2. Test capability of the JSC conical nozzle arc jet tunnel.

\begin{tabular}{|l|l|}
\hline Property & Value \\
\hline \hline Heater Power & $10 \mathrm{MW}$ \\
\hline Test Chamber & $12^{\prime}$ DIA \\
\hline Nozzle Size & Conical 5' DIA to 40" DIA \\
\hline Enthalpy Range & 1500 to $16000 \mathrm{BTU} / \mathrm{lbm}$ \\
\hline Surface Temperature Range & $1000^{\circ} \mathrm{F}$ to $4000^{\circ} \mathrm{F}$ \\
\hline Surface Pressure Range & 20 psf to $400 \mathrm{psf}$ \\
\hline Typical Uses & Stagnation heating, leading edge segment \\
\hline
\end{tabular}




\section{Design Goals and Requirements}

\section{A. Primary Goal}

The primary goal of the arc jet test fixture is to study advanced control surface seal and preloader concepts under simulated reentry heating conditions while evaluating the interaction between the seals and control surface materials. The seals should be tested under conditions representative of the actual reentry environment as shown in Table 1.

\section{B. Modular Seal Cartridge}

The test fixture needs to accommodate several seal configurations with minimal hardware modification. A modular seal carrier component will provide the ability to test the diverse seal shapes and sizes. The seal carrier must be large enough to support the largest envisioned seals and provide enough depth to add preload devices behind the specimens. In addition, the seal carrier section must provide instrumentation near the seal, allowing measurements in close proximity to the specimen regardless of the size of the seal. Finally, a mechanism must be included for preventing flow paths around the ends of the carrier, ensuring proper experimental comparisons can be made between rigid and flexible seals.

\section{Flap}

\section{Modularization}

Depending on the vehicle, designers are considering either CMC (e.g. carbon/silicon carbide $(\mathrm{C} / \mathrm{SiC})$, carbon/carbon $(\mathrm{C} / \mathrm{C})$ ) or tile-insulated aluminum control surfaces. A modular, easy-to-disassemble design also is valuable should difficulty arise during the testing. For instance, static tests have shown that seal materials often bond to advanced CMC materials. ${ }^{7}$ A modular control surface would allow various flap designs to be easily installed in the test fixture.

\section{Flap Movement}

The control surface included in test fixture design must be able to be rotated to various angular positions, and the test fixture should ideally be capable of manipulating the flap position during testing. The position of the control surface affects the flow pattern, temperatures, and pressures near the seal. ${ }^{6}$ Furthermore, movement of the control surface during experiments helps to assess seal wear performance at high temperature.

The use of CMC hot structures for the control surface combined with the desire to manipulate the flap angle during experiments further adds to the design complexity. The temperature of the motor and brake used to rotate the flap must be kept below their respective design values. Attachment means must be provided to allow relative thermal growths between the cool motor drive and hot CMC flap while minimizing heat transfer between these components. Complicating this requirement further, seal specimens must be compressed uniformly in order for their performance to be properly quantified. This means that the flap axis must be maintained in its true position regardless of the thermal growths of the flap drive components.

\section{Angle of Attack}

The thermal and pressure environment to which the seal specimen is exposed is affected by the inclination of the test fixture. Higher temperatures and pressure drops can be obtained by utilizing a high angle of attack in the test fixture. Furthermore, reentry vehicles typically fly at high angles of attack during peak heating, directly exposing the seal gap to the reentry flow. Adjustment of the fixture angle of attack is crucial to simulating reentry conditions and provides a means for manipulating the environment to which the seal and flap are exposed.

\section{E. Yaw Angle}

Depending on the vehicle control surface seal location, seal gaps can be oriented such that they are perpendicular to the flow direction or more parallel to it. The inclusion of an adjustable yaw angle in the test fixture would allow for evaluation of seals when the hot arc jet flow is permitted to travel along the seal gap. In this configuration, hot gas could travel deeper into the gap, reducing the recirculation region above the seal and exposing the specimen to higher heat fluxes and temperatures. 


\section{F. Positional Adjustment}

The arc jet produces a flow which does not have constant properties throughout its cross section. The center of the jet contains significantly higher levels of enthalpy, with JSC estimating that the specific enthalpy in the core of the jet is twice that of the bulk properties. The ability to adjust the position of the test fixture would permit the hottest core of the jet to be focused on different locations both upstream and downstream of the seal location.

\section{G. Instrumentation}

Seal arc jet tests are typically characterized by high gradients of temperature, pressure, and flow velocity. ${ }^{6}$ The test fixture must include instrumentation to record both pressures and temperatures in several locations including far upstream, immediately upstream, immediately downstream, and far downstream of the seal. These sensors would allow characterization of the hypersonic flowfield and provide data for the evaluation of seal performance.

Health monitoring instrumentation is also vital to the survivability of the test fixture. The heat flux into the test hardware has the capacity to damage the fixture in the event of a cooling system failure or similar breakdown. Furthermore, small gaps can exist between various components of the hardware, particularly if the components must move relative to one another. Ingestion of arc jet gases into these gaps presents the possibility of a re-radiation condition. In this circumstance, thermal radiation cannot easily escape the small gap and is instead radiated between the gap walls, raising the temperature to extreme levels. Instrumentation must be provided throughout the fixture, particularly in sensitive gap areas, to monitor the temperatures. Should the temperatures climb to unsafe levels, the arc jet can be shut down before any damage is done to the fixture or facility.

\section{H. Survival of Fixture}

The hot gases produced in the arc jet facility are capable of seriously damaging or destroying portions of the test fixture. A cooling system included in the test fixture would provide the primary defense against this damage. Cool temperatures would be maintained throughout the arc jet fixture structure, instrumentation, and electronic components using cooling water supplied by the facility.

Special attention must be paid to the re-radiation condition described above. The severe heating in gaps is localized to small size scales, and cooling water cannot easily be delivered to these small locations in sufficient quantities to offset the heat load. The best method to prevent damage from localized gap heating is to prevent the hot gases from entering the gaps in the first place, through a combined system of labyrinth seals, positive purge pressure, and shielding.

\section{Fixture Size}

One of the primary concerns expressed by the team at JSC was that a large test fixture could block the flow of the tunnel if it were set to a high enough angle of attack. In this situation, the flow would be deflected away from the tunnel collector duct by the test fixture. The gas would pressurize the test chamber and, if left unchecked, would result in an overexpanded jet. The diameter of the jet at the test fixture would decrease in response to this condition, focusing its enthalpy over a smaller area on the hardware. While safety systems in the arc tunnel control systems automatically shut down the tunnel before these dangerous conditions occur, the occurrence of this condition would prevent successful completion of seal experiments. The test hardware must accomplish its design goals while maintaining a minimal footprint in order to prevent flow blockage situations.

\section{Test Fixture Design and Attributes}

The test fixture design shown in Fig. 3 meets the aforementioned design goals. Some of the major components are called out in Fig. 3(a). The test fixture is capable of supporting a wide variety of seal and flap concepts while providing for movement of the flap during tests. The seal and flap can also be changed out with relative ease. The apparatus is designed to survive the intense arc jet heating via a combination of insulation and cooling systems. Instrumentation is located throughout the fixture to quantify seal performance as well as to monitor the temperature of various locations in the fixture. The following sections describe how the design goals were met for this test fixture. 


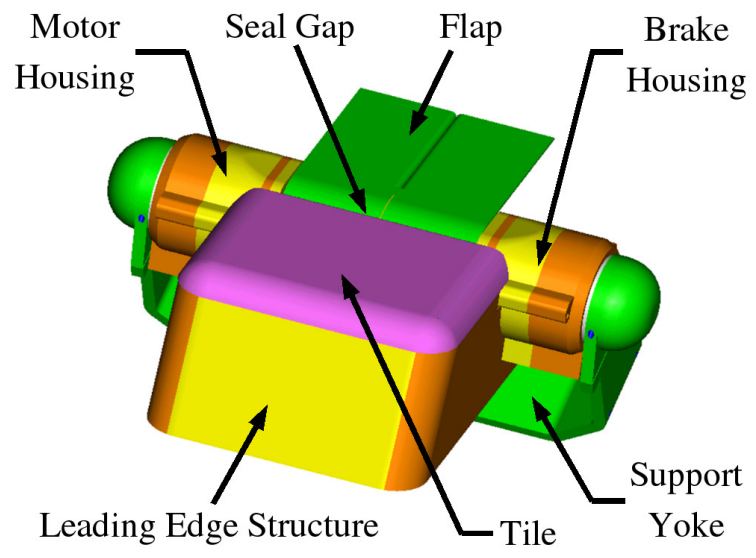

(a) Front view of test fixture.

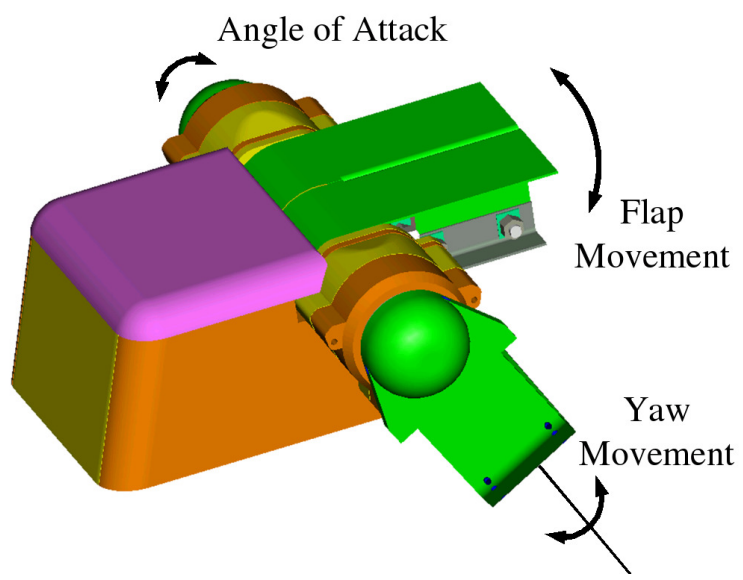

(b) Side view of test fixture.

Figure 3. Main elements of the advanced seal arc jet test fixture

Table 3. Material properties of OFHC copper at room temperature.

\begin{tabular}{|l|l|}
\hline Property & Value \\
\hline \hline Density & $0.323 \mathrm{lb} / \mathrm{in}^{3}\left(8.94 \mathrm{~g} / \mathrm{cm}^{3}\right)$ \\
Modulus of Elasticity & $17,000 \mathrm{ksi}(120 \mathrm{GPa})$ \\
Yield Stress & $10 \mathrm{ksi}(69 \mathrm{MPa})$ \\
UTS & $32 \mathrm{ksi}(220 \mathrm{MPa})$ \\
Thermal conductivity & $226 \mathrm{BTU} / \mathrm{ft} \cdot \mathrm{hr} \cdot{ }^{\circ} \mathrm{F}(391 \mathrm{~W} / \mathrm{m} \cdot \mathrm{K})$ \\
\hline
\end{tabular}

\section{A. Leading Edge}

The forward portion of the test fixture, referred to as the leading edge, contains the majority of the test hardware and was the focus of the design process. This component is the base to which the remaining components attach and contains the majority of the fixture instrumentation. Furthermore, the leading edge section is exposed to the most severe heat flux, temperature, and chemical effects of the components constituting the test fixture.

\section{Description}

The leading edge section is shown as an exploded view in Fig. 4. The leading edge is formed primarily from oxygenfree high conductivity (OFHC) copper, selected because of a combination of its yield strength and its high thermal conductivity. The material properties of this material are presented in Table 3. The corners and edges of the fixture include 1-in. radii to help reduce the heat transfer in these regions and keep the temperatures within material limits.

Fig. 5 illustrates the cooling system designed into the leading edge. The majority of the cooling is performed by

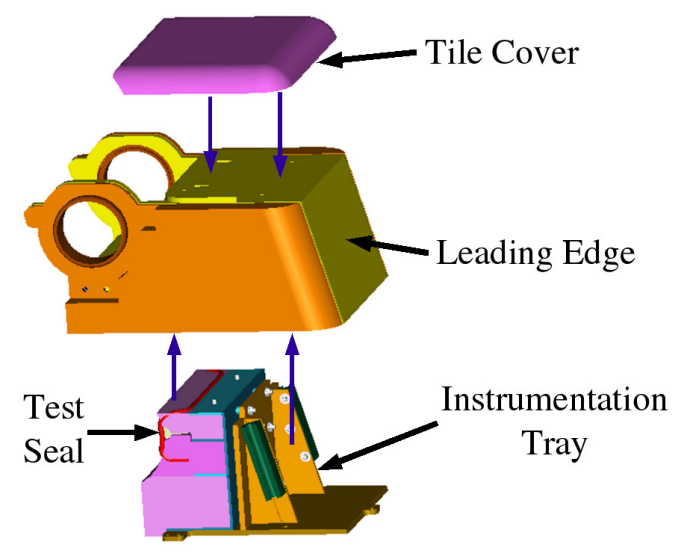

Figure 4. Primary components of leading edge section, including tile cover plate, leading edge structure, and removable instrumentation tray with installed seal cartridge module. 
channeling water throughout the leading edge and into the side-mounted motor and brake housings (described below). Cooling passages are milled into various leading edge pieces during fabrication, which are then brazed together to form water-tight cooling passages. The water-cooling is focused primarily along the front of the leading edge, particularly in the stagnation region. A second concentration of water-cooling passages is located circumferentially around the motor and brake housings. The water-cooling system is designed to move enough water through the fixture to prevent it from boiling. To accomplish this, the cooling system is designed to maintain the copper temperature at no more than $200^{\circ} \mathrm{F}$, although local hot spots (distanced from the cooling passages) approaching $350^{\circ} \mathrm{F}$ are permissible. The anticipated material temperatures are discussed further in Section IV.

A high-density insulating tile (e.g. BRI-20) covers the leading edge section from a short distance upstream of the stagnation point to the seal gap. The tile prevents significant heat transfer to the underlying copper structure, providing a twofold advantage. First, by avoiding active cooling along the surface of the leading edge, the flow temperature and heat flux can be maximized in the downstream seal and flap regions. Additionally, the tile reduces the amount of cooling water required by the fixture, benefiting the regions which require active cooling.

\section{Heating Calculation at Stagnation Point}

The leading edge is exposed to the highest heating rates on the test fixture primarily due to the presence of the stagnation point region in the near-center of the flow stream. An estimate of the stagnation point heating provided the fundamental information used in the design of the fixture cooling system.

The first set of heating calculations were performed by JSC. The Boundary Layer Integral Matrix Procedure (BLIMPK) code was used to solve the boundary layer heating

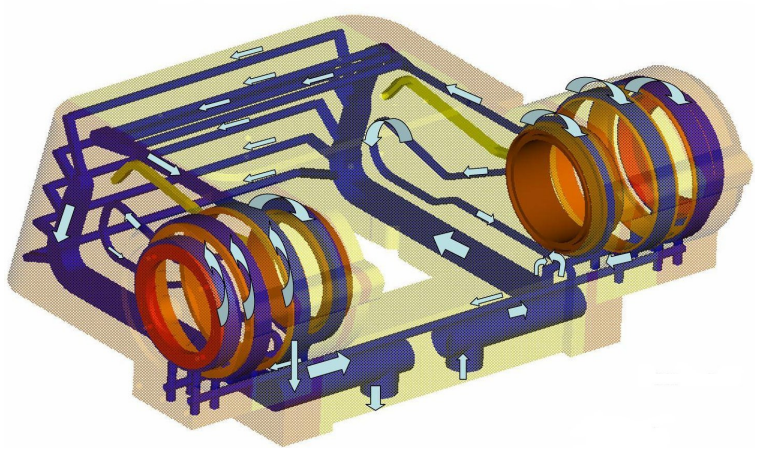

Figure 5. Cooling passages milled and brazed into leading edge and flap transmission housings, as viewed from the fixture top and rear. The ring-like structures provide cooling to the motor (right) and brake (left). Blue passages carry water while yellow passages carry air. The arrows indicate water flow directions.

on the fixture. The Non-equilibrium Arc Tunnel Analysis (NATA) code was used to calculate the output properties of the arc jet and set the boundary conditions for BLIMPK. The results showed the stagnation heat flux as $41 \mathrm{BTU} / \mathrm{sec} \cdot \mathrm{ft}^{2}$ $\left(460 \mathrm{~kW} / \mathrm{m}^{2}\right)$ using the 15 -in. $(0.38-\mathrm{m})$ nozzle with the test hardware located 8 in. $(0.2 \mathrm{~m})$ from the nozzle exit plane. A radiative temperature equilibrium balance calculation predicted a peak temperature of $2750^{\circ} \mathrm{F}(1780 \mathrm{~K})$ at the stagnation point. A similar calculation for a 10 -in. $(0.25-\mathrm{m})$ nozzle with the hardware set 10 in. $(0.25 \mathrm{~m})$ from the nozzle exit plane resulted in a stagnation heating value of $48 \mathrm{BTU} / \mathrm{sec} \cdot \mathrm{ft}^{2}\left(540 \mathrm{~kW} / \mathrm{m}^{2}\right)$. A radiative temperature equilibrium calculation using this value predicted a temperature of $2880^{\circ} \mathrm{F}(1860 \mathrm{~K})$ at the stagnation point. Fig. 6 presents the radiative equilibrium temperature calculations performed by JSC for the upper fixture surface for both the 10-in. diameter conical nozzle and the 15-in. diameter conical nozzle. For both nozzles, the fixture angle of attack was assumed to be $60^{\circ}$. The length variable, $X^{\prime}$, is measured along the exposed surface of the fixture with the stagnation point defined as $X^{\prime}=0$.

A Fay-Riddel stagnation point calculation was performed by GRC in parallel with the calculations completed by JSC. This calculation assumed a nozzle diameter of $15 \mathrm{in}$. and idealized the shape of the leading edge section as a two-dimensional cylinder. For this shape, the stagnation point heat flux was estimated using a Fay-Riddel analysis, shown as

$$
q_{w}^{\prime \prime}=0.570 \operatorname{Pr}^{-0.6} C_{w}^{0.1} \sqrt{\rho_{e} \mu_{e}\left(\frac{d u_{e}}{d x}\right)_{s}}\left(i_{w}-i_{0 e}\right),
$$

where $q_{w}^{\prime \prime}$ is the heat flux per unit area, Pr is the Prandtl number, $\rho_{e}$ is the gas density at the boundary layer edge, $\mu_{e}$ is the gas viscosity at the boundary layer edge, $\left(\frac{d u_{e}}{d x}\right)_{s}$ is the isentropic velocity derivative at the boundary layer edge, $i_{w}$ is the gas specific enthalpy at the wall, and $i_{0 e}$ is the specific stagnation enthalpy at the boundary layer edge. $C_{w}$ is a constant defined in terms of the gas density and viscosity both at the wall and at the boundary layer edge. Details of the calculation can be found in Section A in the Appendix. Ignoring nonequilibrium effects and using the thermodynamic state information provided by JSC, the stagnation heating rate was $q_{w}^{\prime \prime}=410 \mathrm{~kW} / \mathrm{m}^{2}$, which compares well with the results for the 15-in. nozzle results produced by the BLIMPK code. 


\section{Heating Calculation for Side Walls}

The heat transfer to the side walls of the leading edge was estimated by utilizing principles of high speed convective boundary layer heat transfer. The method used in this study is outlined in Holman, ${ }^{8}$ although minor modifications were introduced to simplify the calculations. The typical assumptions for boundary layer flow (i.e. one-directional flow) were assumed to apply. The integrated heating rate was determined using the convection equation modified to use specific enthalpy instead of temperature, shown as

$$
q^{\prime \prime}=\frac{\bar{h}}{c_{p}}\left(i_{w}-i_{a w}\right)
$$

where $q^{\prime \prime}$ is the heat flux, $\bar{h}$ is the convective heat transfer coefficient, $c_{p}$ is the specific heat of the gas, $i_{w}$ is the gas specific enthalpy at the wall, and $i_{a w}$ is the specific enthalpy at the adiabatic wall temperature. The details of this calculation can be found in Section B in the Appendix. Ignoring nonequilibrium effects and the effects of chemical recombination on the properties of the gas (but including the chemical enthalpies), the integrated heating rate on the leading edge side walls was calculated to be $q^{\prime \prime}=11 \mathrm{BTU} / \mathrm{sec} \cdot \mathrm{ft}^{2}\left(130 \mathrm{~kW} / \mathrm{m}^{2}\right)$.

\section{Wood Model}

The size of the test fixture is such that it may cause blockage of the arc jet tunnel and prevent successful seal tests. To this end, a full-scale wood model of the test fixture was fabricated and delivered to the JSC arc jet facility. Preliminary testing of such a wood model typically lasts for a few seconds and provides information about flow patterns, hot spots, and the potential for tunnel blockage. Fabrication of the actual test fixture will commence upon successful completion of the wood model tests. While combustion of the wood is impossible in the low-pressure, low-oxygen environment of the facility, the few seconds of hot gas exposure will introduce scorch patterns into the wood. These patterns can be used for final modification of the cooling system to ensure that the actual test fixture temperature remains within its design envelope.

\section{B. Seal Cartridge}

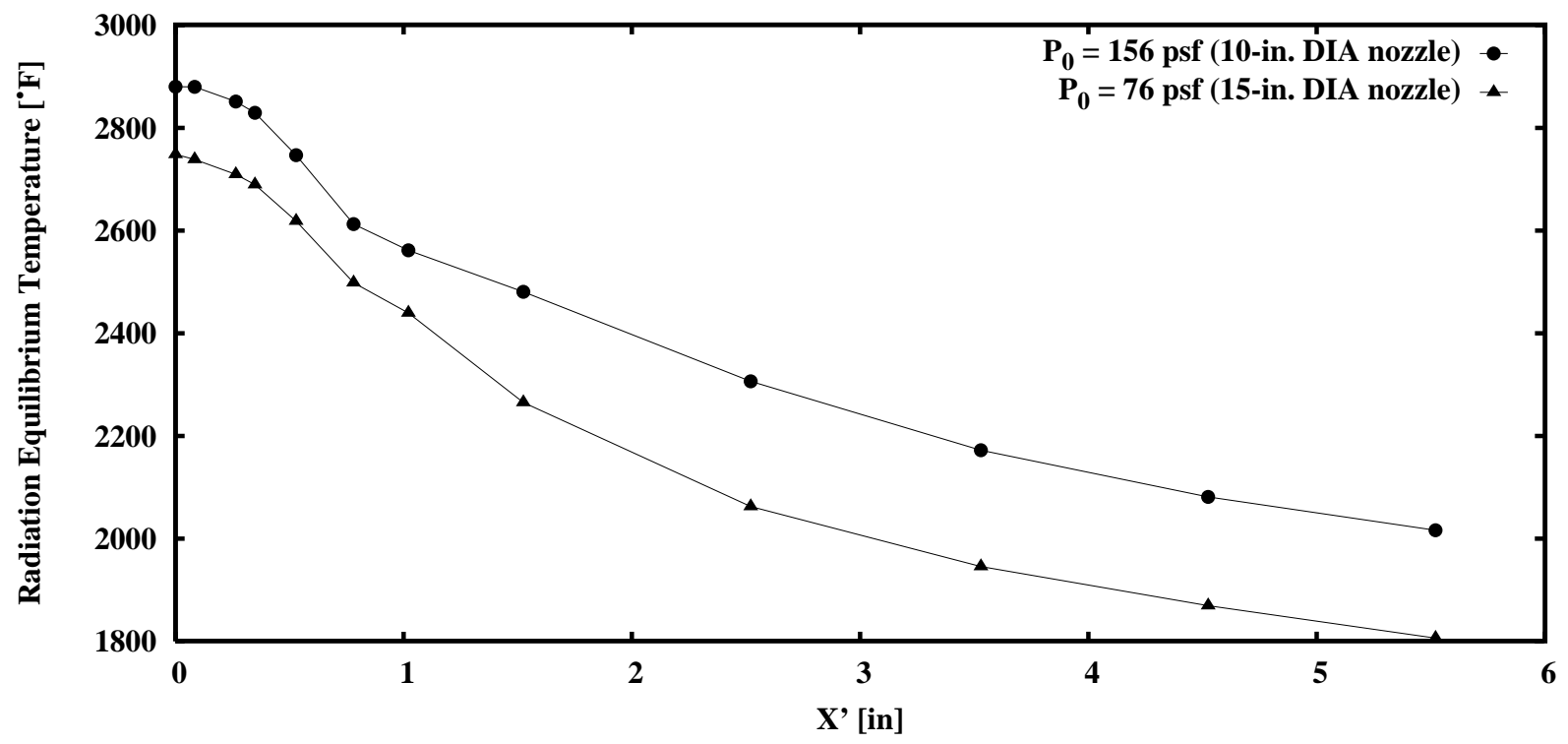

Figure 6. Leading edge 2D heating estimate calculated by JSC using the BLIMPK code for both a 10-in. diameter nozzle and a 15-in. diameter nozzle for a fixture angle of attack of $60^{\circ}$. The variable $X^{\prime}$ is measured along the upper surface with $X^{\prime}=0$ as the stagnation point. 
One of the primary goals in designing the test article was to allow a variety of different seal designs to be tested in a modular, removable seal cartridge. This cartridge is composed of any one of a series of seal holders that attach to a tray that is installed on rails into the leading edge housing, as shown in Fig. 4 and 7. Each seal cartridge is designed to hold a specific seal design including the seal itself and any preloading device that supports the seal. The maximum supported seal size is 8 in. $(0.2 \mathrm{~m})$ long and has a crosssection that fits into a circumscribed 3-in. $(0.08-\mathrm{m})$ circle. Two examples of seal cartridges supporting different seal designs are shown in Fig. 8.

The seal cartridges are required to survive the flow conditions to which the seals are exposed, and therefore are fabricated from blocks of high-temperature insulating material. The cartridges are concave in the cove area in order to conform to the shape of the control surface flap. This profile also sets the size of the gap in which the seals must

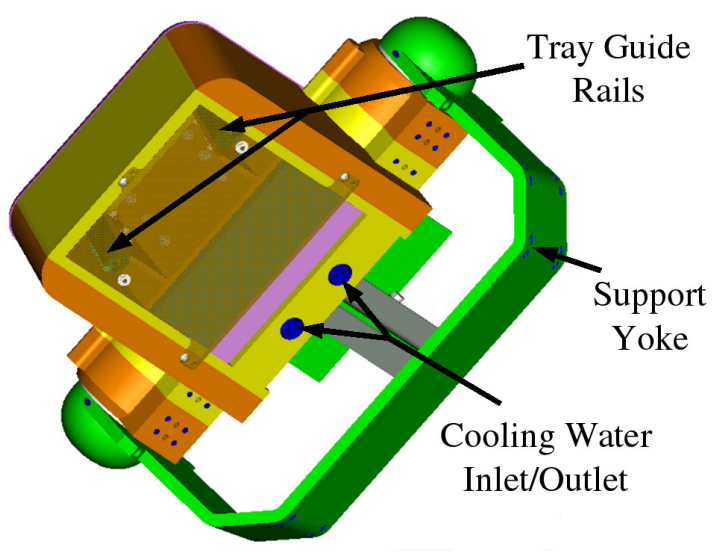

Figure 7. Bottom of test fixture with instrumentation tray rendered semi-transparent to illustrate mounting rails. fit during testing. The baseline gap is 0.25 in. $(6.4 \mathrm{~mm})$, although other gap sizes are possible with modifications to the seal cartridge design.

The seal cartridge allows instrumentation (i.e. thermocouples, pressure taps) to be placed immediately upstream and downstream of the seal. The wiring for the instruments is passed through holes in the insulating blocks to the back side of the seal cartridge. The wiring is then bundled together and passed out of the instrumentation tray, where it joins the other connectors (cooling, electronics) and travels through the structural attachment to the arc jet facility. While the instrumentation port is not shown in the model, it will be located near the two cooling water ports shown in Fig. 7.

The removable tray provides the base for the seal cartridge and associated instrumentation. The tray slides along two rails in the leading edge section, providing alignment for the tray and assuring the correct preload force vector. The tray also functions as a protective cover to prevent the hostile arc jet environment from damaging the instrumentation wiring, electrical connections, and cooling system feeds.

One of the most critical features of the seal cartridge is the secondary seal that blocks the flow of hot gases past the ends of the test seals. The secondary seal is placed to prevent the hot arc jet gases from passing around the edges of the seal cartridge and into the interior of the leading edge, thereby damaging the test fixture. Fig. 8(a) demonstrates the secondary seal location on the ceramic wafer seal cartridge. The baseline secondary seal layout starts below one end of the test seal, loops up over the top of the cartridge, and wraps down around the other end of the test seal. This seal path ensures that the hot gases flow through the test seal and not around its ends or behind the cartridge. For the illustrated case with ceramic wafer seals, the secondary seal is seated on wafers $0.25 \mathrm{in}$. $(6.4 \mathrm{~mm})$ shorter than the rest of the wafer stack. These shortened wafers are mounted on hard stops, unlike the wafer stack which is mounted on a spring preload device. This ensures that the secondary seal is properly compressed without disturbing the compression in the seal stack. The seal cartridge shown in Fig. 8(b) contains a secondary seal, but it is not shown in the illustration.

\section{Flap}

The test fixture has been designed in a modular fashion so that different flap designs and materials can be tested with minimal modifications to the test fixture. This allows the seal-to-control surface interface to be evaluated in an arc jet environment for different combinations of seal materials, flap materials, and flap surface roughnesses. In particular, material compatibility tests can be performed to examine potential bonding between candidate seal and flap materials at high temperatures.

The baseline control surface flap for the test fixture is shown in Fig. 9, and it is shown semi-transparent in order to illustrate the internal torque transmission components. This flap, provided by Materials Research \& Design, Inc. through a contract under NASA's Next Generation Launch Technology program, is an assembly of torque tubes, panels, and flanges that are held together by fasteners. All of these components are made of carbon fiber reinforced silicon carbide $(\mathrm{C} / \mathrm{SiC})$ ceramic matrix composite material and are coated with cbs coating. The flap is approximately 7.9 in. $(0.20 \mathrm{~m})$ wide and 10.2 in. $(0.26 \mathrm{~m})$ long from its leading edge to its trailing edge with a leading edge torque tube radius of $2.2 \mathrm{in}$. $(0.56 \mathrm{~m})$. The length of the flap from the top of the torque tube to the trailing edge is 8 in. $(0.20$ $\mathrm{m})$. The sealing surface is provided by a face sheet wrapped around the outer tube. While the test fixture was designed using this flap as a baseline model, the fixture design provides for the easy installation and testing of other flap designs. 


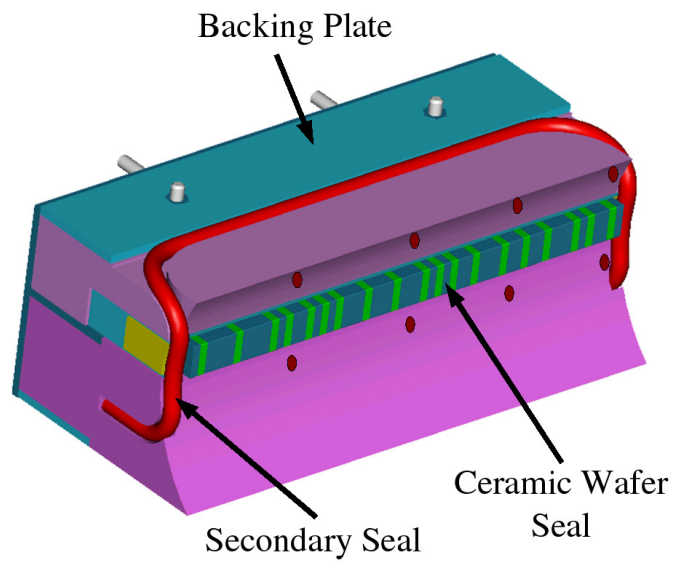

(a) Seal carrier designed for use with ceramic wafer seals. A secondary seal reduces end gap flows and protects internal fixture components.

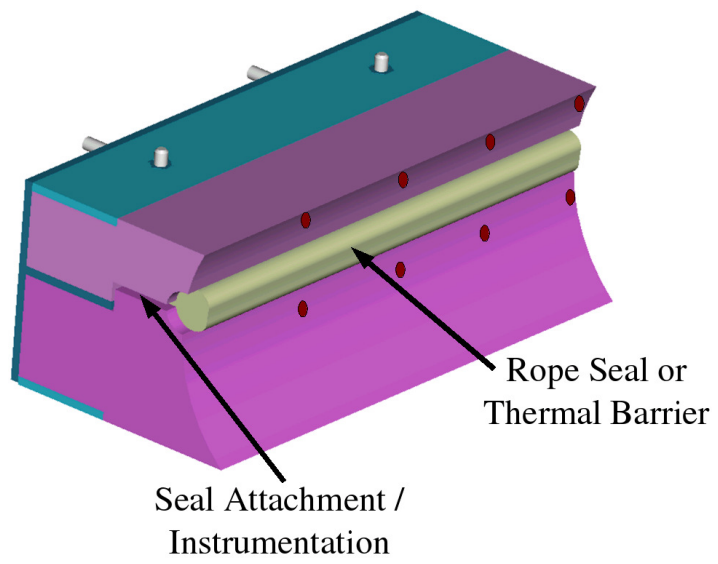

(b) Seal carrier designed for use with rope seal/thermal barrier specimens. The peripheral end seal is not shown.

Figure 8. Example seal carrier designs for ceramic wafer seals and rope seals/thermal barriers. Red dots indicate approximate locations for modular instrumentation.

\section{Motor and Brake}

The test fixture design requirements call for a flap which is able to move while exposed to the simulated reentry conditions. This includes aerodynamic loads applied to the flap by the arc jet flow stream as well as frictional loads applied by the seals while the flap is in motion. The selection of a proper motor was therefore vital to fulfilling the design goals of the test fixture. Once the flap has been rotated into the desired position during testing, it is important that it remains in that position without putting excessive static loads on the motor. When the flap is moved to its proper position, the brake engages and prevents further motion of the control surface. One unique feature of the brake is that it is engaged when unpowered, so that a voltage signal is required to disengage the brake. In the unlikely event that the wiring to the brake is severed, the brake will remain engaged, keeping the flap from moving and keeping the fixture safe.

The motor and brake were selected based upon their size as well as the torque required to move the flap under the arc jet conditions. The following calculations assumed the flow

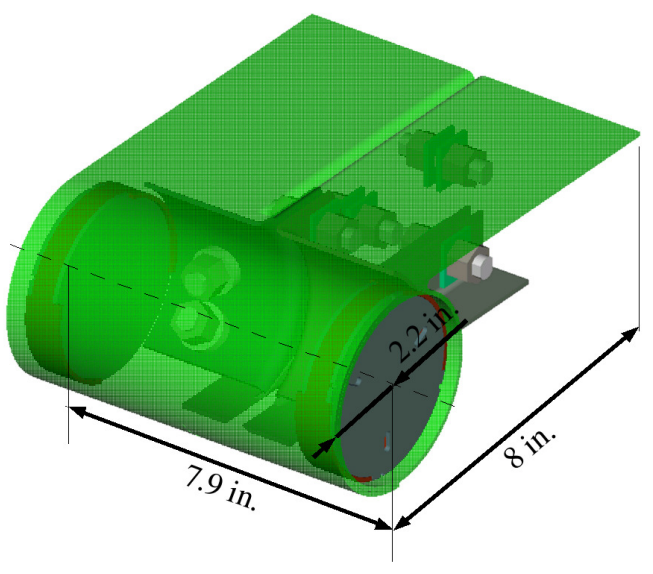

Figure 9. Test fixture CMC flap. The flap material is rendered semi-transparent to illustrate the torque transmission mechanism. reaches stagnation over the entire surface of the flap; that is, the flap is oriented at $90^{\circ}$ from the flow direction. The torque on the flap was calculated by

$$
\tau=p_{0} L w c_{x}+F_{N, \text { seal }} R w
$$

where $p_{0}$ is the stagnation pressure, $L$ is the length of the flap of $8 \mathrm{in}$. $(0.20 \mathrm{~m}), w$ is the width of the flap of 8 in. $(0.20$ $\mathrm{m}), R$ is the flap radius of $2.2 \mathrm{in}$. $(0.056 \mathrm{~m})$, and $c_{x}$ is the pressure centroid of the flap and is defined as $L / 2 \mathrm{for}$ a rectangular flap. $F_{N \text {, seal }}$ is the frictional force generated per unit length of seal and is assumed to be $5 \mathrm{lbf} / \mathrm{in}$. (9 N/cm). The weight of the flap $(\sim 2.2 \mathrm{lb}(9.8 \mathrm{~N})$ ) was not considered in this calculation because its contribution was deemed to be minimal. Based on information provided by JSC, the stagnation pressure of the jet was assumed to be 186 psf ( 8.91 $\mathrm{kPa}$ ). The reduction in the stagnation pressure due to the front bow shock wave was ignored to provide a conservative 


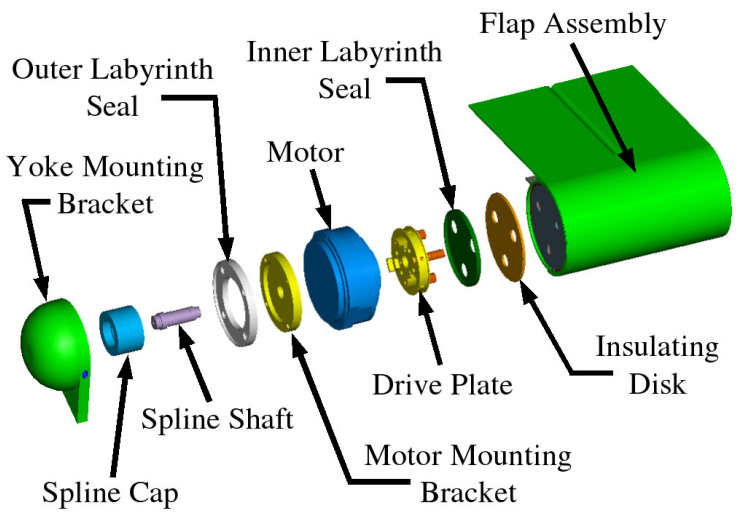

(a) Flap transmission system for motor side.

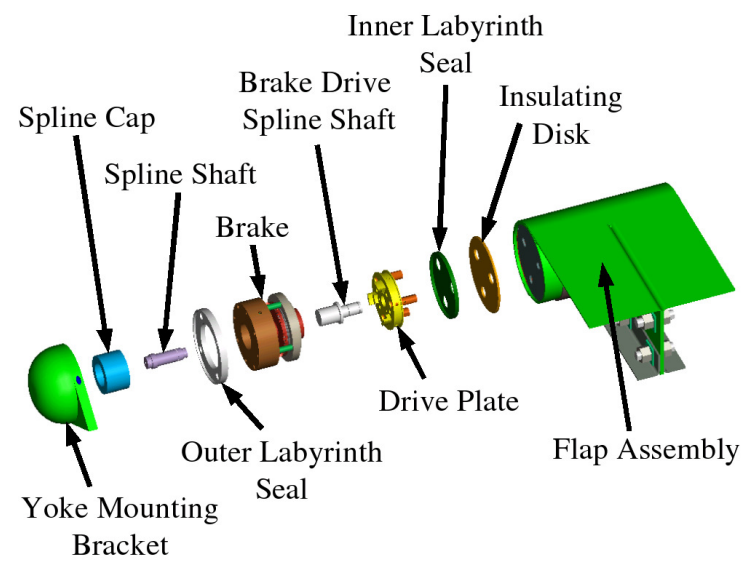

(b) Flap transmission system for brake side.

Figure 10. Flap transmission system, shown for both motor and brake sides

torque estimate. For an 8 in. by $8 \mathrm{in}$. flap, the torque on the flap generated by a combination of stagnation pressure and seal friction was $420 \mathrm{in} \cdot \mathrm{lb}(47.5 \mathrm{~N} \cdot \mathrm{m})$.

The selected motor is a DC electrical motor connected to a harmonic drive which has a reduction ratio of 100. The motor and harmonic drive are rated for a maximum repeated output torque of $470 \mathrm{in} \cdot \mathrm{lb}(53 \mathrm{~N} \cdot \mathrm{m})$ and a maximum momentary output torque of $760 \mathrm{in} \cdot \mathrm{lb}(86 \mathrm{~N} \cdot \mathrm{m})$, satisfying the flap torque requirements. The selected brake is rated to hold against $1200 \mathrm{in} \cdot \mathrm{lb}(140 \mathrm{~N} \cdot \mathrm{m})$ of torque with angular indexing increments of $1.5^{\circ}$.

\section{E. Flap Drive and Transmission}

The transmission of torque from the motor to the flap posed several difficulties, the most critical of which was that at a temperature of roughly $2400^{\circ} \mathrm{F}$, the $\mathrm{C} / \mathrm{SiC}$ flap must connect to cool metallic components while also remaining centered and positioned at the correct angles with respect to the connecting components. The transmission system which drives the hot CMC control surface is designed meet the challenges imposed upon it by the high temperature gradients and differences in thermal expansion of the various fixture materials.

\section{Description}

Two exploded views of the flap, motor, brake, and torque transmission hardware are shown in Fig. 10. The transmission system on the motor side is illustrated in Fig. 10(a) and is composed of (moving from the outside toward the flap) a yoke mounting bracket, a spline cap, a spline shaft, an outer labyrinth seal, a motor mounting bracket, the motor, a drive plate with three press-fit cooled pins, an inner labyrinth seal, and the flap with its attached torque transmission system. Cooled housings, not shown in the above figures, contain all components inboard the outer labyrinth seal. The labyrinth seal prevents the hot arc jet gases from entering the gap between the housing and the yoke mounting bracket. The brake transmission system, shown in Fig. 10(b), is nearly identical to that on the motor side, with the brake replacing the motor and a brake drive spline shaft included in between the brake and drive plate. Additionally, a wave spring is incorporated in the motor-side of the transmission and used for axial preload of the flap, but it is not shown in the figure.

The cooled drive interface assembly has several unique features that:

(a) allow it to transmit torque from the motor to the flap while minimizing heat conduction to the motor,

(b) connects metallic components to the hot CMC components while allowing for differences in thermal growths and minimizing stresses, and

(c) centers the hot flap relative to the cooler drive mechanism regardless of temperature difference. 
The cooled drive interface is composed of a metal drive disk with three pins that engage a slotted ceramic disk assembly. The slots in the disk are oriented radially allowing relative thermal growths between the cool and hot parts while maintaining precise centering.

Cooled Disk The side of the cooled disk that faces the motor has three L-shaped brackets that center the assembly against the motor and create a standoff that minimizes heat conduction to the motor. The disk is attached to the motor by six bolts. The perimeter of the disk contains a channel that is supplied with cooling air by ports in the housing that surrounds the assembly. The cooling air flows into six passages located $60^{\circ}$ from each other and drilled from the perimeter of the disk toward its center. Three of these passages mate up with cross-drilled holes that direct the cooling air toward the motor on one side of the disk and toward the wave spring and labyrinth seal on the other side. The remaining three passages provide cooling air to the cooled drive pins that are located $120^{\circ}$ from each other. A cut-away section view of the drive plate is shown in Fig. 11.

DRIVE PINS The cooled drive pins are the key components that permit transmission of torque from the motor to the flap. As shown in Fig. 11, the drive pins are formed by an inner tube that is inserted into an outer housing. This figure also shows the cooling scheme for the pins in which cooling air

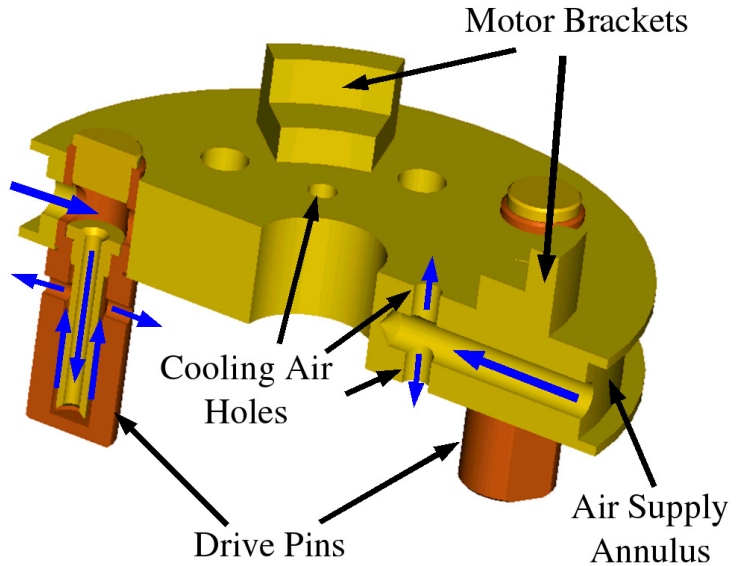

Figure 11. Cut-away view of drive plate with blue arrows showing direction of air flow. Included in the illustration is a section view of a cooled drive pin. Opposite the pin is a section view of a cooling air passage, which supplies cooling air to the motor and inner labyrinth seal. enters at the base of the pin, flows past its hot tip, and then exits through a pair of holes just above the surface of the disk. The design of these pins is based on a prior design for cooled actuator rods reported by Lattime, et al. ${ }^{9}$ The results for the thermal analyses performed on the cooled drive interface assembly will be discussed later in this paper. All of the components for this assembly are made of Inconel 718.

INNER LABYRINTH SEAL A labyrinth seal made of Inconel 718 is inserted between the cooled drive interface assembly and the hot ceramic components that mate directly with the flap. The labyrinth seal mates with an annular groove in the sidewall of the main test fixture housing to seal the gap between the flap and the sidewall and restrict the flow of hot arc jet gases into the motor and brake chambers. A positive purge of cooling air past the labyrinth seal further ensures that hot gases will not enter these chambers. Three slots in the labyrinth seal allow the drive pins to pass through and engage with the CMC drive assembly.

INSULATING DisK A ceramic insulating disk sits immediately inboard of the labyrinth seal. Formed from silicon nitride, the 0.1-in. ( $3 \mathrm{~mm}$ ) thick insulating disk minimizes conduction from the hot flap to the motor. Like the labyrinth seal, the insulating disk also has three slots to allow the drive pins to pass through it. The positive purge of cooling air past the labyrinth seal flows along the pins and through these slots to prevent hot gasses originating at the flap from moving into lower temperature regions.

Ceramic Disk Assembly Fig. 12 illustrates the CMC disk assembly, which is made up of an outermost slotted disk, a notched ring, an innermost solid disk, and an inner tube in the flap assembly. These parts are supplied by Materials Research \& Design, Inc. (MR\&D) along with the flap, all of which are made of C/SiC with a carbon-boronsilicon (cbs) coating. The outermost disk is $0.1 \mathrm{in} .(3 \mathrm{~mm})$ thick and has three slots in it that engage with the drive pins. The slots are arranged $120^{\circ}$ apart and are slightly radially oversized to allow for thermal growth between the hot CMC plates and cooled metallic pins. The innermost disk, also 0.1 in. $(3 \mathrm{~mm})$ thick, does not have any slots in it. This solid disk prevents any cooling air that flows through the slotted disks from entering the flap and cooling it, thereby ensuring the highest possible temperatures in the flap-to-seal interface region. Notches on the perimeter of the outer disk mate with notches on the outer face of the ring. Furthermore, the $0.2 \mathrm{in}$. $(5 \mathrm{~mm})$ deep notches on the inner ring face mate with both the notched inner disk as well as the notches on the inner flap tube inside the flap to transmit torque from the CMC drive assembly to the flap. Ultimately, the true position of the flap axis is preserved independently of temperature differences between the $\mathrm{C} / \mathrm{SiC}$ flap and cooled Inconel 718 pins by allowing the diameter 
of the flap to grow around the three pins. By preventing changes in the position of the flap due to thermal expansion, the transmission system achieves the goal of near-uniform seals compression along the length of the seal specimen.

The hardware layout on the brake-side is symmetric to that on the motor-side except for the wave spring, drive plate, and motor. The brake drive spline shaft engages with a spline on the inner diameter of the drive plate, rotationally locking the shaft to the plate and allowing the brake to transmit torque through the plate and into the flap. The end of the brake drive spline shaft protrudes through the drive plate and functions as a hard stop to align the flap and torque transmission hardware axially. The wave spring on the motor-side of the flap serves as a compliant member, holding the flap assembly against the hard stop while accommodating thermal growths and differences in thermal expansion between the flap and the surrounding housing.

In the unlikely event that the motor becomes overheated during testing and stops functioning, a device was designed to be installed in place of the motor so that the flap position could still be adjusted manually in between tests. This device does not allow the flap position to be adjusted during testing

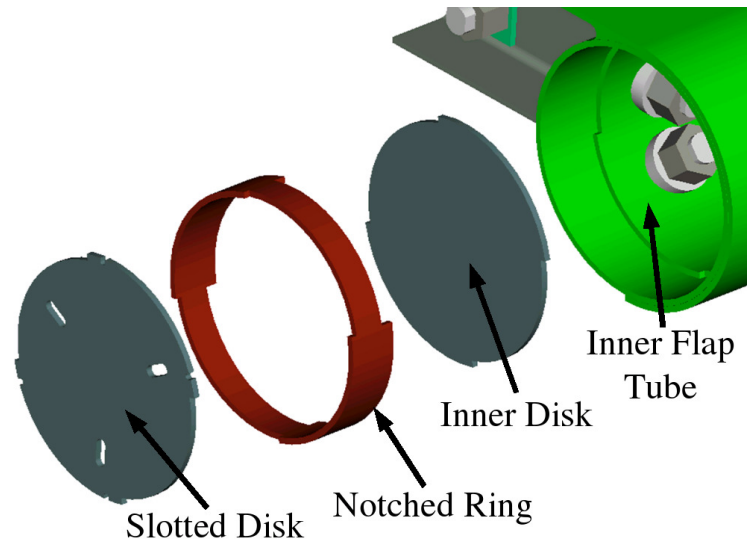

Figure 12. CMC flap drive assembly consisting of slotted disk, notched ring, inner disk, and inner flap tube. like the motor would, but it achieves the minimal requirement of allowing for an adjustable flap angle which can be set between tests.

\section{Motor Insulation}

Several different methods of insulating the motor and brake from the high flap temperatures are employed in the transmission system. The silicon nitride insulating disc provides the first barrier against heat flow into the motor. This disc blocks the radiation and convection heat transfer mechanisms from the $2400^{\circ} \mathrm{F}$ flap to the cooler transmission and motor components, so that the primary means of transporting heat is conduction through the three drive pins. The temperature of the pins is regulated by the air cooling system, which convects heat away from the pins. The heated air is vented through the labyrinth seal, thereby transporting the heat away from the temperature-sensitive components. The air cooling system also cools the center of the drive plate assembly and forming an effective heat block for the motor. The motor itself is thermally isolated from the neighboring drive plate by three insulating spacers, which also serve to locate the drive plate with respect to the motor.

\section{F. Motor and Brake Housing}

The addition of a motor and brake system represent the first known instance of placing such equipment directly in the path of the arc jet flow at JSC. Without properly protecting these sensitive devices via cooling systems, the electronic components would be damaged by the hot arc jet gases.

\section{Description}

The motor housing is shown in Fig. 13 along with the motor-side transmission system described earlier. The housings are constructed of the same OFHC copper used in the leading edge, and are formed by an assembly of smaller components that have been brazed together. Cooling water flows through three circumferential passages in the housings to maintain a cool temperature in the flap transmission system, particularly in the motor and brake components. Furthermore, the housings introduce an air supply, which cools the torque transmission components and also maintains a positive purge pressure to prevent the ingestion of arc jet gases as previously discussed.

Each side of the test fixture supports one housing around the near-symmetric flap transmission assembly. The motor housing is shown in Fig. 13 and is rendered transparent to illustrate how the housing fits around the transmission system. The housings are partially recessed into the leading edge to reduce the frontal area of the fixture, minimizing the potential for the fixture to block the arc jet tunnel flow. The housings are coaxial to the axis of rotation for the flap and the angle of attack adjustment, allowing the underlying equipment modules to be placed in the same location. 


\section{Heating Calculations}

The flow coming from the arc jet tunnel does not have constant thermal properties; the fluid in the center of the jet has a higher specific enthalpy than the fluid near the boundaries of the flow. The heating calculations for the motor and brake housings use the same assumptions as the leading edge calculations, with the bulk fluid enthalpy equal to half of the enthalpy in the center of the jet. However, Fig. 14 demonstrates that the motor and brake housings are near the boundary of the jet where the fluid has the lowest specific enthalpy. This indicates that heating calculations performed with the bulk fluid properties should provide a conservative heating estimates on the housings.

A conservative estimate of the heating can be provided by assuming that the bulk gas properties apply at the housing locations as well as at the leading edge. A Fay-Riddel calculation, identical to that performed on the leading edge component except with a radius of $2.5 \mathrm{in} .(6.4 \mathrm{~cm})$, resulted in a heating rate of $22 \mathrm{BTU} / \mathrm{s} \cdot \mathrm{ft}^{2}\left(260 \mathrm{~kW} / \mathrm{m}^{2}\right)$. It should

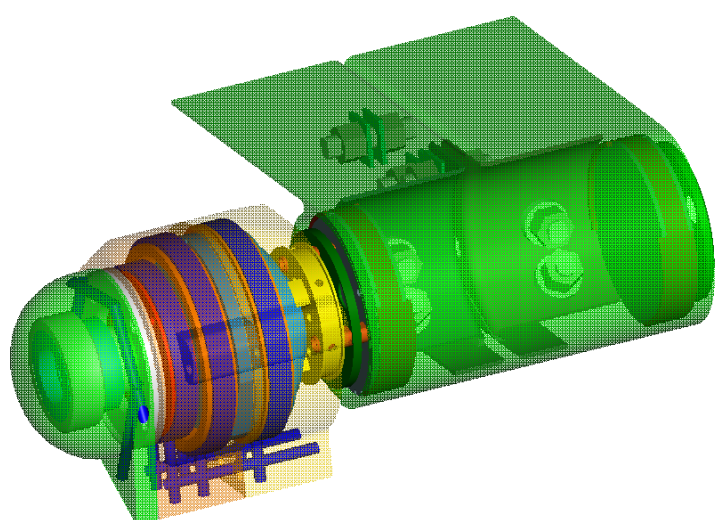

Figure 13. Motor housing rendered transparent to show underlying flap transmission system on the motor side. again be noted that due to the fluid properties near the boundaries of the jet, this value is a conservative estimate.

\section{G. Angle of Attack Adjustment}

A dual-spline system, assembled from the yoke mounting bracket, spline cap, spline shaft, and motor mounting bracket shown in Fig. 10, provides the capability to change the angle of attack of the fixture. Angular increments of $6^{\circ}$ can be obtained by pushing the spline cap toward the flap, which disengages a spline and frees the fixture to rotate. A spring mounted between the spline cap and motor housing reengages the spline when the cap is released. Finer angular increments can be obtained by removing the yoke mounting bracket from the support yoke, manipulating the spline between the yoke mounting bracket and the spline cap, and then reattaching the yoke mounting bracket to the support yoke. This motion allows $10^{\circ}$ rotational increments, and when combined with the $6^{\circ}$ increments from the spline cap/spline shaft, total fixture angular increments of $2^{\circ}$ can be achieved.

Fig. 10(b) illustrates that the brake transmission has no motor mounting bracket. The spline shaft on this side of the fixture is free to rotate independently of the underlying transmission system. The pivot pin at this location serves as an axis of rotation and as a component to locate the fixture, but plays no role in setting the fixture angle of attack.

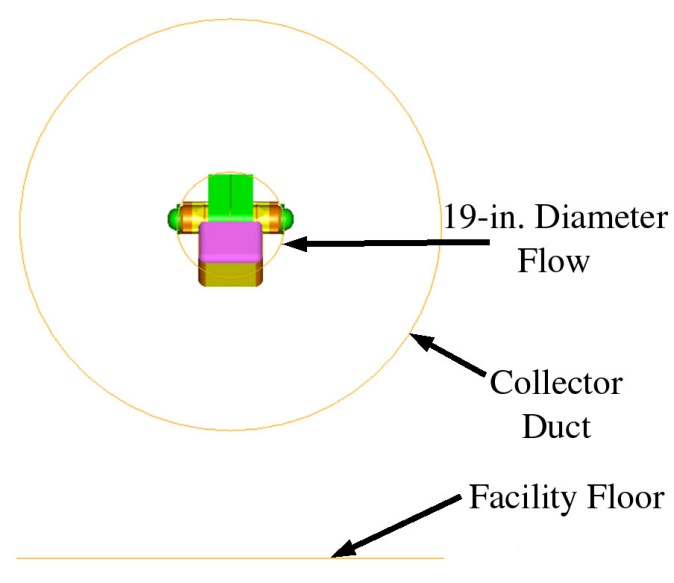

Figure 14. Front view of test fixture as seen through arc jet nozzle. The inner circle has a 19-in. (0.48-m) diameter and represents the estimated jet diameter after expanding from a 15-in. (0.38-m) diameter nozzle.

\section{H. Yaw Adjustment}

A mechanism for adjusting the fixture yaw angle is located between the supporting structure that holds the fixture in the arc jet flow (called the "sting arm"), and the supporting yoke. This feature allows the testing of seal response to flow moving along the seal gap. The adjustment mechanism consists of two washers with teeth clocked in $5^{\circ}$ intervals. A bolt passes through the middle of the washers and connects to the support yoke on one side and to the sting arm on the other. 
The yaw angle on the test fixture is adjusted by loosening the securing bolt, thus allowing the toothed washer to freely rotate. The entire fixture can then be manually placed at the desired yaw angle. The fixture is then secured by tightening the bolt and reengaging the teeth on the washer.

The yaw adjustment mechanism is designed to produce pure yaw change when the test fixture angle of attack is set to $60^{\circ}$. The adjustment will still function when the angle of attack is set to a value other than $60^{\circ}$, although the rotation will not be pure yaw and may require compensation by moving the fixture in other directions.

\section{Yoke and Support System}

The interface between the test fixture and sting arm is provided by the yoke. The yoke supports the test fixture, secures it to the sting arm, and routes cooling water, air, and instrumentation lines to and from the test fixture. The yoke is designed to permit easy removal of the test fixture from the arc jet facility so that the fixture may be serviced on a workbench. This is accomplished by removing four bolts from the yoke mounting brackets and disconnecting the cooling water, air, electronics, and instrumentation lines. The yoke is water-cooled throughout its structure, including through the yoke mounting brackets. The end caps are not water-cooled, instead relying on conductive cooling to maintain a safe temperature.

\section{J. Sting Arm}

A new sting arm assembly is being developed to hold the hardware in the arc jet flow. A position adjustment feature is being added to the sting arm which allows modification of the fixture position with respect to the axis of the jet. The arc jet facility includes an actuation mechanism capable of moving the attached fixture in the direction of the nozzle over a 12-in. (0.30-m) stroke. Spacer blocks may be added to the base of the sting arm (outside of the flow stream and high heating region) to modify the length of the arm. This adjustment allows the hot core of the arc jet flow to be focused on various positions of the test hardware. For example, some tests may require the jet core to be focused on the seal gap, while other tests may require the hottest portion of the jet to impact the flap.

\section{K. Instrumentation}

Seal performance is evaluated via temperature and pressure measurements taken around the seal. Instrumentation is also required in critical locations of the test fixture for health monitoring purposes to ensure the apparatus does not overheat during testing. Tables 4 and 5 provide a list of some of the instrumentation in the test fixture including a brief description of the location for each measurement. Note that many of the instruments are attached to the modular seal cartridge, and the positions of these instruments can change for different seal types. This permits measurements to be made in close proximity to the seal regardless of seal size. Additional modular instruments may be added to the seal cartridges depending on the requirements for a particular seal specimen. Baseline locations of these modular instruments are shown as red dots in Fig. 8.

Seal performance is quantified through the changes in properties measured across the seal. Properties far upstream of the seal (i.e. 1.5 in. $(3.8 \mathrm{~cm})$ ) can be compared to measurements immediately upstream of the seal (i.e. 0.5 in. $(1.2$ $\mathrm{cm})$ ) to determine what effects the length of the seal cove has on the fluid properties. Furthermore, the measurement location immediately upstream of the seal is compared to the measurement immediately downstream of the seal (i.e. 0.5 in. $(1.2 \mathrm{~cm}))$ to demonstrate the effectiveness of the seal. The measurement location far downstream of the seal (i.e. 1.5 in. $(3.8 \mathrm{~cm})$ ) demonstrates any property changes in the cove region behind the seal. Furthermore, several of the measurements located along the flow direction are duplicated across the width of the test fixture. For example, for the instrument location $0.5 \mathrm{in} .(1.2 \mathrm{~cm})$ above the seal, thermocouples are located on center, $2 \mathrm{in} .(5 \mathrm{~cm})$ right and left of center, and at one end of the seal. This allows the temperature distribution along the length of the seal to be monitored during testing. Similar arrangements allow the pressure distribution along the length of the seal to also be recorded.

While much of the instrumentation is dedicated to recording data on seal performance, health monitoring thermocouples are placed in various locations in the test hardware. These instruments are used to ensure that critical components of the fixture do not exceed rated temperatures and can be used for test termination. Examples include thermocouples placed at several locations inside of the leading edge chamber, under the tile cover, inside the motor/brake housings, and on the sting arm (i.e. ID\#s 23-29 in Table 4). The temperature readings from these locations are monitored during a test and help to ensure proper functioning of the cooling system.

Temperature measurements are planned for various locations on the flap. The baseline flap design includes thermocouples along the outside of its front tube to measure seal cove temperatures. In addition, thermocouples 
Table 4. Preliminary list of thermocouples and their respective locations. Modular instrument positions can be changed for different seals.

\begin{tabular}{|c|c|c|}
\hline ID \# & Location/description & $\begin{array}{c}\text { Permanent(P) } \\
\text { Modular(M) }\end{array}$ \\
\hline 1 & CMC flap, in cove, closest to seal & $\mathrm{P}$ \\
\hline 2 & CMC flap, in cove, above \#1 & $\mathrm{P}$ \\
\hline 3 & CMC flap, in gap between panels, further upstream & $\mathrm{P}$ \\
\hline 4 & CMC flap, in gap between panels, further downstream & $\mathrm{P}$ \\
\hline 5 & CMC flap, on top surface of flap, further upstream & $\mathrm{P}$ \\
\hline 6 & CMC flap, on top surface of flap, further downstream & $\mathrm{P}$ \\
\hline 7 & Leading edge upper surface, 1 " from cove, near edge & $\mathrm{P}$ \\
\hline 8 & Leading edge upper surface, 1 " from cove, 2 " right of center & $\mathrm{P}$ \\
\hline 9 & Leading edge upper surface, 1 " from cove, on center & $\mathrm{P}$ \\
\hline 10 & Leading edge upper surface, 1 " from cove, 2 " left of center & $\mathrm{P}$ \\
\hline 11 & In cove, $1.5 "$ above seal, $2 "$ right of center & $\mathrm{P}$ \\
\hline 12 & In cove, $1.5 "$ above seal, on center & $\mathrm{P}$ \\
\hline 13 & In cove, $1.5 "$ above seal, $2 "$ left of center & $\mathrm{P}$ \\
\hline 14 & In cove, $0.5 "$ above seal, near edge & M \\
\hline 15 & In cove, $0.5 "$ above seal, 2 " right of center & M \\
\hline 16 & In cove, $0.5 "$ above seal, on center & M \\
\hline 17 & In cove, $0.5 "$ above seal, $2 "$ left of center & M \\
\hline 18 & In seal groove behind seal & M \\
\hline 19 & In cove, 0.5 " below seal, near edge & M \\
\hline 20 & In cove, 0.5 " below seal, 2 " right of center & M \\
\hline 21 & In cove, $0.5 "$ below seal, on center & M \\
\hline 22 & In cove, 0.5 " below seal, 2 " left of center & M \\
\hline 23 & Inside leading edge \#1 & $\mathrm{P}$ \\
\hline 24 & Inside leading edge \#2 & $\mathrm{P}$ \\
\hline 25 & On sting arm & $\mathrm{P}$ \\
\hline 26 & Leading edge stagnation point & $\mathrm{P}$ \\
\hline 28 & On motor & $\mathrm{P}$ \\
\hline 29 & On brake & $\mathrm{P}$ \\
\hline 30 & Water supply & $\mathrm{P}$ \\
\hline 31 & Water outlet & $\mathrm{P}$ \\
\hline
\end{tabular}

are used on the top flap surface and in the gap between the panels that form the flap to measure the top surface temperatures.

The cabling for the leading edge and seal cartridge instruments are routed out the back side of the leading edge and into the yoke. The cabling is shielded from the arc jet flow by the high angle of attack of the leading edge such that the instrumentation lines are never directly exposed to the harsh arc jet environment. The instrumentation lines from the flap are fed directly to the yoke and out through the sting arm.

\section{Analysis}

A three-dimensional (3D) ANSYS finite-element model of the test fixture was assembled based on the fixture geometry and heating rates determined during the design process. The model was used in the design of the cooling system as well as to verify that the fixture would survive the intense heating imparted to it by the arc jet facility. The 
Table 5. Preliminary list of pressure taps and their respective locations. Modular instrument positions can be changed for different seals.

\begin{tabular}{|c|l|c|}
\hline ID \# & Location/description & $\begin{array}{c}\text { Permanent(P) } \\
\text { Modular(M) }\end{array}$ \\
\hline \hline 1 & Leading edge upper surface, 1" from cove, 2" right of center & $\mathrm{P}$ \\
2 & Leading edge upper surface, 1" from cove, on center & $\mathrm{P}$ \\
\hline 3 & In cove, 1.5" above seal, 2" right of center & $\mathrm{P}$ \\
4 & In cove, 1.5" above seal, on center & $\mathrm{P}$ \\
5 & In cove, 0.5" above seal, 2" right of center & $\mathrm{M}$ \\
6 & In cove, 0.5" above seal, on center & $\mathrm{M}$ \\
7 & In cove, 0.5" below seal, 2" right of center & $\mathrm{M}$ \\
8 & In cove, 0.5" below seal, on center & $\mathrm{M}$ \\
\hline 9 & In cavity downstream of seal, 1/2" diameter tube & $\mathrm{P}$ \\
\hline 10 & Water supply & $\mathrm{P}$ \\
11 & Water outlet & $\mathrm{P}$ \\
\hline
\end{tabular}

primary goals of the ANSYS analysis were to determine the temperatures, stresses, and displacements of the various fixture components under conditions generated by the arc jet facility.

\section{A. Model Setup}

\section{Leading edge}

The leading edge portion of the model contained heating rates imparted by the arc jet flow, cooling provided by the internal water passages, and structural loads imparted by its own weight and its connected components. This region of the model was assumed to be constructed from copper, with the assumed properties shown in Table 3.

The heating rates applied to the leading edge were taken from the heating analyses described in Section IIIA-2. The copper portions of the top surface and stagnation point region were assumed to be perfectly insulated by the tile panel cover and hence had no applied heat transfer. However, the front face was assumed to have an applied heat transfer of $460 \mathrm{~kW} / \mathrm{m}^{2}$, the maximum calculated value of the stagnation point heating. The two side faces were assumed to have a heat flux of $130 \mathrm{~kW} / \mathrm{m}^{2}$ as defined by the side wall heat transfer calculations described in Section IIIA-3. The rear and bottom faces of the leading edge were assumed to have negligible heat transfer. For modeling purposes, the top tile cover is assumed to be a perfect insulator, and zero heat flux is assumed over the top surface of the leading edge. The tile is not shown in the results because of this assumption.

The value of the coefficient of convective heat transfer in the cooling channels was calculated using a log-mean temperature difference method with an input water temperature of $70^{\circ} \mathrm{F}(294 \mathrm{~K})$ and an output water temperature of $200^{\circ} \mathrm{F}(366 \mathrm{~K})$.

\section{Motor housings}

The heat transfer to the motor housings was assumed to be a uniform $22 \mathrm{BTU} / \mathrm{s} \cdot \mathrm{ft}^{2}\left(260 \mathrm{~kW} / \mathrm{m}^{2}\right)$ on the half exposed to the flow, while the downstream half was assumed to have a negligible heat flux. The cover located on the side of the housing was assumed to have a heat flux of $12 \mathrm{BTU} / \mathrm{s} \cdot \mathrm{ft}^{2}\left(130 \mathrm{~kW} / \mathrm{m}^{2}\right)$, identical to that of the side walls. Fabricated from the same copper as the leading edge, the material properties of the motor housings were assumed as the values listed in Table 3. The water cooling passages were assumed to have convective coefficients of heat transfer identical to that of the leading edge cooling system.

\section{Drive system}

The majority of heat transfer through the drive system originated at the flap, set to a constant temperature of $2400^{\circ} \mathrm{F}$ $(1600 \mathrm{~K})$. The labyrinth seal was assumed to have bonded contact with the ceramic disk assembly inside the flap. On the brake side of the fixture, the labyrinth seal was also in sliding contact with the brake spine shaft, serving as a hard 


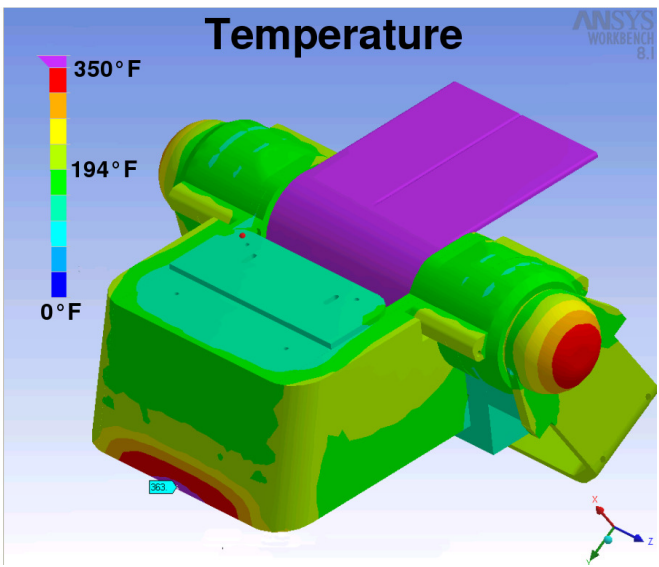

(a) Temperature distribution over test fixture.

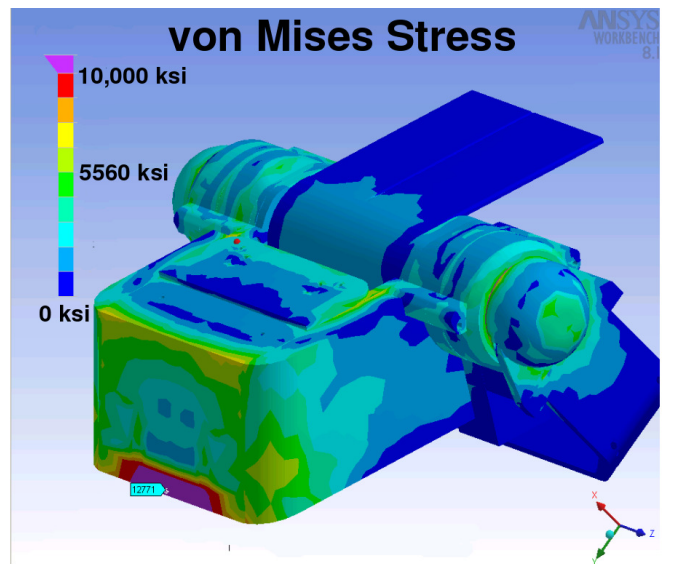

(b) von Mises stresses calculated in test fixture.

Figure 15. Temperature and stress distributions over exposed test fixture surfaces. Top tile cover is not shown and is assumed to be a perfect insulator.

stop for the flap assembly. The three Inconel 718 drive pins were assumed to have sliding contact with the flap ceramic disk assembly slots. Each pin was assumed to have an internal air flow rate of $10 \mathrm{cfm}(280 \mathrm{l} / \mathrm{min})$.

\section{B. Results}

The calculated temperature profile of the test fixture is shown in Fig. 15(a). The highest copper temperature of $363^{\circ} \mathrm{F}(457 \mathrm{~K})$ occurs in the center of the forward lower corner of the leading edge. The ends of the motor housings are also at temperatures of approximately $350^{\circ} \mathrm{F}(450 \mathrm{~K})$.

Fig. 15(b) shows the von Mises stresses calculated in the fixture. These stresses are primarily thermal stresses based on the temperature gradients present in the fixture. The maximum stresses occur inside of the drive transmission system, which is described below. In the context of the figure, the largest stresses are on the leading edge portion of the fixture are coincident with the highest temperatures. The maximum stresses in Fig. 15(b) are above the yield stress for copper, however, the loads are primarily due to thermal deformation. This region can be expected to undergo local yielding when first heated. Once the heating cycle is complete, the fixture will unload, and the yielded region will revert into a compressive residual stress condition. Subsequent heating cycles will bring the region out of compression and into tension while remaining below the yield point. This is common design practice for pressure vessels under secondary loading, where stress values twice that of yielding are permitted for such secondary loads. Furthermore, at the time of publication, the analysis is being repeated with a heating load similar to that seen in Fig. 6. This reduced heating load approximates actual arc jet conditions better than the uniform conservative heat load used in the current results, and is expected to result in lower stress values.

The largest thermal gradients in the test fixture occur in the flap drive and transmission system, particularly in the cooled Inconel 718 drive pins. Fig. 16 demonstrates the high thermal gradients in the pins. Occurring in the span of roughly half an inch, the temperature drops from the $2400^{\circ} \mathrm{F}$ flap temperature to roughly $100^{\circ} \mathrm{F}$ on the drive plate, as shown in Fig. 16(c). The thermal stresses developed in the pins are shown in Fig. 16(b). The figure also shows exaggerated thermal displacements. The maximum stresses are coincident with the maximum temperatures. As the hot side expands, the cooler region of the pin resists the expansive motion, subjecting the expanded region to compression. The stresses developed in the pin are well within the yield tensile stress of Inconel 718 of $142 \mathrm{ksi}(980 \mathrm{MPa})$ at $1200^{\circ} \mathrm{F}$, and the compressive nature of these stresses assists in resisting creep failure.

\section{Summary}

NASA GRC has developed a unique test apparatus capable of evaluating advanced control surface seal and flap designs under simulated reentry heating conditions in NASA JSC's arc jet test facility. This test apparatus is capable 


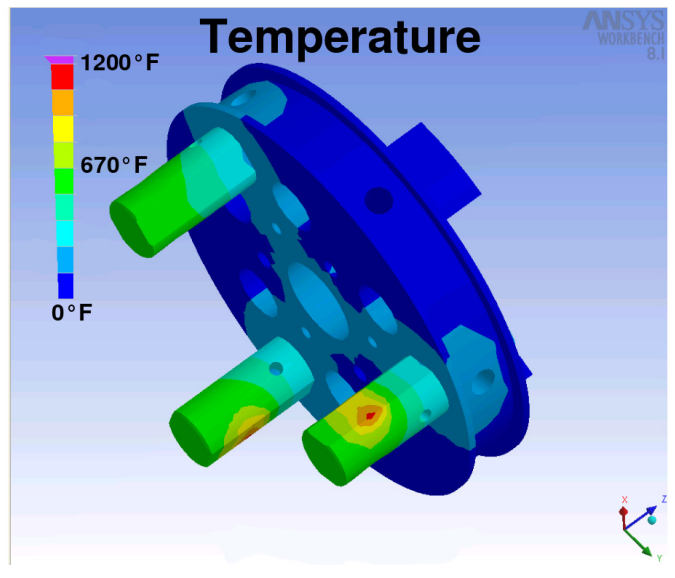

(a) Temperature profiles on drive pins and drive plate.

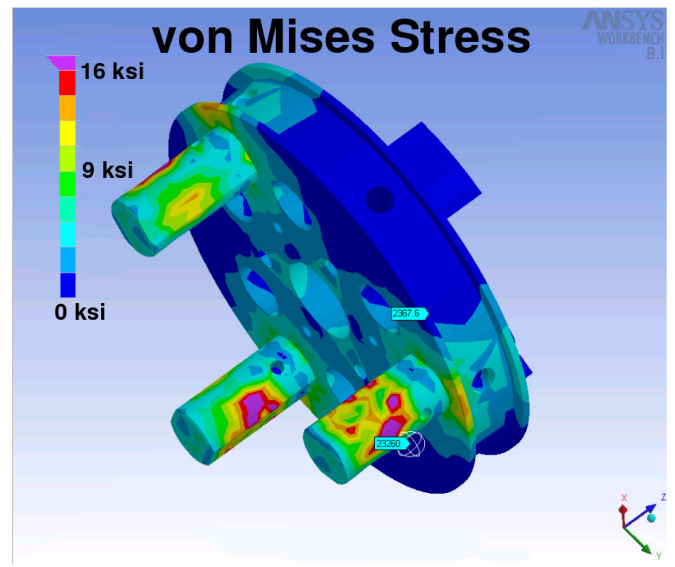

(b) Thermal stresses developed in drive pins. The maximum stresses are believed to be compressive and are well within the capabilities of Inconel 718. Note: displacements are exaggerated.

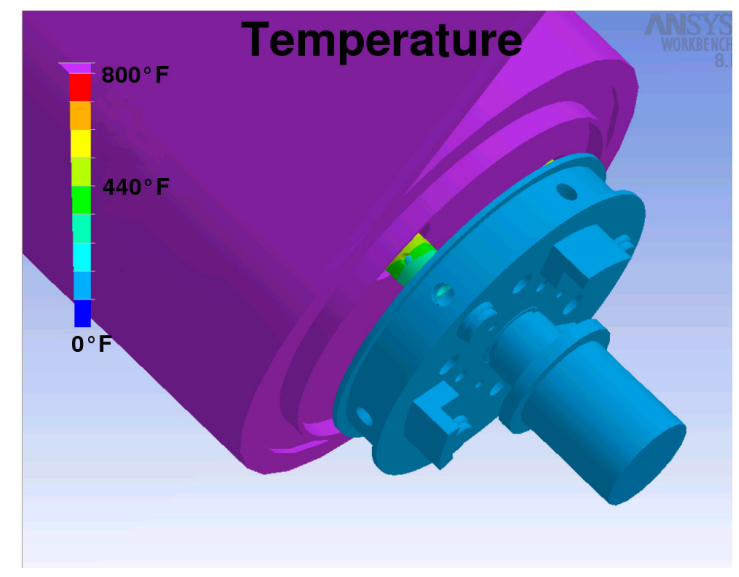

(c) Zoomed view of temperatures in flap, labyrinth seal, drive pins, drive plate, and brake spline.

Figure 16. High temperature gradients exist in the air-cooled drive pins

of testing different seal designs using modular, removable seal cartridges in the presence of high enthalpy flow to simulate reentry conditions. The control surface flap on the fixture can be remotely rotated during testing to vary the seal cove environment and test scrubbing damage and material compatibility between the seals and flap. While the baseline flap is made of $\mathrm{C} / \mathrm{SiC}$, the modular design easily allows other flap designs and materials to be evaluated. Mechanisms have been incorporated so that the test fixture angle of attack, yaw angle, and vertical and horizontal positions with respect to the nozzle can all be adjusted manually for each test. A full suite of instrumentation provides data on seal performance including temperature and pressure drops across the seal test specimen.

The test fixture was designed to minimize the potential for equipment damage or injury. The flap movement is constrained with a braking system which must be energized to allow movement. This not only prevents movement of the flap based on the torque generated by the tunnel pressure, but also ensures by its design the flat will not accidentally rotate in the event of an electrical failure. Water cooling maintains all transmission hardware (e.g. motor, brake) and the leading edge copper components well within their operating temperatures. Air purge is used effectively to cool the 
drive pins and purge the labyrinth seals to prevent arc jet gases from overheating rotating interfaces. Health monitoring instrumentation is provided throughout the fixture to allow for emergency shutdown of the arc jet facility in the event of cooling system failure or similar breakdown. A tile cover ensures that the cooled copper does not experience excessive heating and that the flow is not overly cooled before it impinges on the seal.

The advanced seal test fixture represents a major development in testing advanced seal and control surface concepts in simulated reentry heating conditions. The seal test fixture provides a unique combination of modular features, test parameter variability, and safety in a convenient package.

\section{Appendix}

\section{Nomenclature}

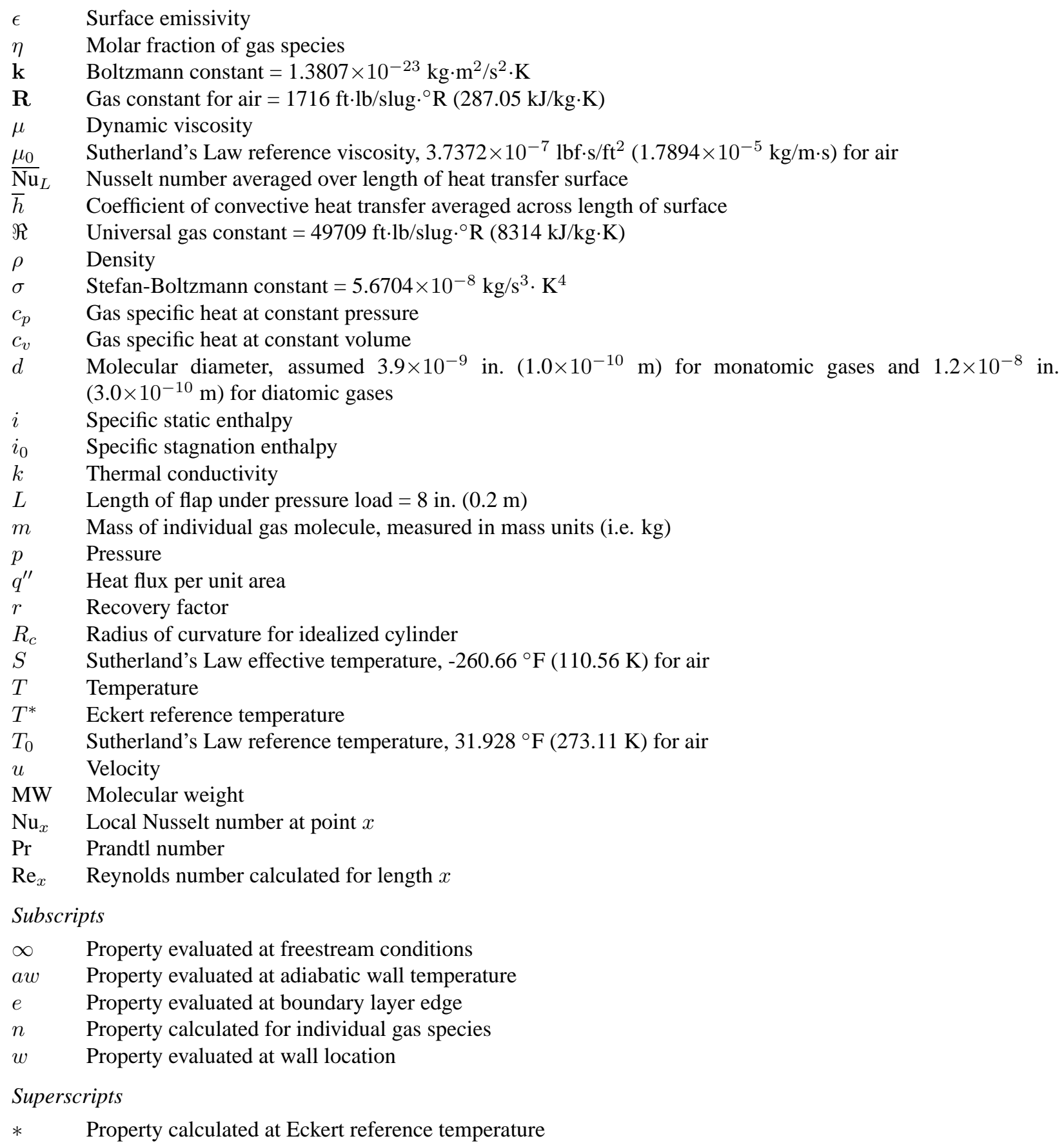




\section{A. Leading Edge Heating at Stagnation Point}

The stagnation point heating was determined using a Fay-Riddel calculation. This calculation assumed a nozzle diameter of $15 \mathrm{in} .(0.38 \mathrm{~m})$ and idealized the shape of the leading edge section as a two-dimensional cylinder. For this shape, the stagnation point heat flux was estimated using Equation 1, repeated here as

$$
q_{w}^{\prime \prime}=0.570 \operatorname{Pr}^{-0.6} C_{w}^{0.1} \sqrt{\rho_{e} \mu_{e}\left(\frac{d u_{e}}{d x}\right)_{s}}\left(i_{w}-i_{0 e}\right),
$$

where $C_{w}$ is defined as

$$
C_{w}=\frac{\rho_{w} \mu_{w}}{\rho_{e} \mu_{e}} .
$$

The isentropic velocity derivative was approximated using Newtonian flow assumptions as

$$
\left(\frac{d u_{e}}{d x}\right)_{s}=\frac{1}{R_{c}} \sqrt{\frac{2\left(p_{e}-p_{\infty}\right)}{\rho_{e}}}
$$

For the above calculations, the boundary layer edge properties were taken as the values immediately downstream of the shock wave. It should be noted that for these calculations, a chemistry correction factor was not included because the nonequilibrium chemical distribution was not known. Based on experimental evidence, JSC recommended that the averaged bulk thermal properties of the jet be used instead of the centerline maximum condition for the leading edge heating calculation. The bulk properties were estimated to be half of the centerline condition reported by JSC.

The thermodynamic state of the gas upstream of the shock wave is presented in Table 6 while the state of the gas downstream of the shock wave is shown in Table 7. The thermodynamic condition at the wall is shown in Table 8. In each of these tables, parameters used in the heating estimations are appropriately labeled. A conservative estimate of enthalpy was found by assuming the wall acted as a fully catalytic surface and that the gas was cooled to the wall temperature. This implied that the gas mixture at the wall was identical to atmospheric air. The gas density at the wall was calculated using the ideal gas relation for air,

$$
\rho_{w}=\frac{p_{w}}{\mathbf{R} T_{w}} .
$$

Other parameters used in the Fay-Riddel heating calculation are shown in Table 9. With the thermodynamic state information at the three locations plus the other parameters, the Fay-Riddel stagnation point heat flux was $q^{\prime \prime}=$ $36 \mathrm{BTU} / \mathrm{s} \cdot \mathrm{ft}^{2}\left(410 \mathrm{~kW} / \mathrm{m}^{2}\right)$, which compares well with the results for the 15 -in. nozzle results produced by the BLIMPK code.

With the heat flux known, a radiation balance was performed at the stagnation point to determine the maximum temperature. The radiation balance was performed without a recovery factor (see Equation 8) in order to obtain the maximum temperature and provide a bounding case. Assuming a recovery factor of $r=0.86$, the radiative equilibrium temperature decreased by less than $4 \%$, demonstrating that this factor could safely be neglected.

The radiation equation, solved for the surface temperature, is

$$
T=\sqrt[4]{\frac{q^{\prime \prime}}{\epsilon \sigma}}
$$

The panel material was assumed to be a coated thermal tile (e.g. BRI-20) with an emissivity of $\epsilon=0.9$, resulting in a stagnation point radiative equilibrium temperature of $2600^{\circ} \mathrm{F}(1700 \mathrm{~K})$. This compared well with the stagnation point results provided by JSC, shown in Fig. 6 . The tile material is capable of surviving at temperatures up to $2800^{\circ} \mathrm{F}(1800$ $\mathrm{K})$, demonstrating that the insulating panel is capable of safe operation at the test fixture stagnation point.

\section{B. Heating Calculation for Side Walls of Leading Edge}

\section{Heat Transfer Model}

The heat transfer to the side walls of the leading edge was estimated by utilizing principles of high speed convective boundary layer heat transfer. The method used in this study is outlined in Holman, ${ }^{8}$ although minor modifications were introduced to simplify the calculations. The typical assumptions for boundary layer flow (i.e. one-directional flow) 
Table 6. Thermodynamic state of gas before shock wave

\begin{tabular}{|l|l|}
\hline \multicolumn{1}{|c|}{ Property } & \multicolumn{1}{c|}{ Value } \\
\hline \hline Density & $6.68 \times 10^{-6} \mathrm{lbm} / \mathrm{ft}^{3}\left(1.07 \times 10^{-4} \mathrm{~kg} / \mathrm{m}^{3}\right)$ \\
Pressure $\left(p_{\infty}\right)$ & $0.501 \mathrm{psf}(24.0 \mathrm{~Pa})$ \\
Velocity & $14000 \mathrm{ft} / \mathrm{s}(4300 \mathrm{~m} / \mathrm{s})$ \\
Enthalpy & $730 \mathrm{BTU} / \mathrm{lbm}\left(1.7 \times 10^{6} \mathrm{~J} / \mathrm{kg}\right)$ \\
\hline
\end{tabular}

Table 7. Thermodynamic state of gas after shock wave

\begin{tabular}{|l|l|}
\hline \multicolumn{1}{|c|}{ Property } & \multicolumn{1}{|c|}{ Value } \\
\hline \hline Density $\left(\rho_{e}\right)$ & $6.93 \times 10^{-5} \mathrm{lbm} / \mathrm{ft}^{3}\left(1.11 \times 10^{-3} \mathrm{~kg} / \mathrm{m}^{3}\right)$ \\
Pressure $\left(p_{e}\right)$ & $38.7 \mathrm{psf}(1860 \mathrm{~Pa})$ \\
Velocity & $1380 \mathrm{ft} / \mathrm{s}(420 \mathrm{~m} / \mathrm{s})$ \\
Enthalpy $\left(h_{e}\right)$ & $4700 \mathrm{BTU} / \mathrm{lbm}\left(1.1 \times 10^{7} \mathrm{~J} / \mathrm{kg}\right)$ \\
\hline
\end{tabular}

Table 8. Thermodynamic state of gas at wall

\begin{tabular}{|l|l|}
\hline \multicolumn{1}{|c|}{ Property } & \multicolumn{1}{|c|}{ Value } \\
\hline \hline Density $\left(\rho_{w}\right)$ & $1.27 \times 10^{-4} \mathrm{lbm} / \mathrm{ft}^{3}\left(2.04 \times 10^{-3} \mathrm{~kg} / \mathrm{m}^{3}\right)$ \\
Pressure $\left(p_{w}\right)$ & $42.8 \mathrm{psf}(2050 \mathrm{~Pa})$ \\
Velocity & $0 \mathrm{ft} / \mathrm{s}(0 \mathrm{~m} / \mathrm{s})$ \\
Enthalpy $\left(h_{w}\right)$ & $0.15 \mathrm{BTU} / \mathrm{lbm}(350 \mathrm{~J} / \mathrm{kg})$ \\
Temperature $\left(T_{w}\right)$ & $170^{\circ} \mathrm{F}(350 \mathrm{~K})$ \\
\hline
\end{tabular}

Table 9. Parameters used in Fay-Riddel calculation

\begin{tabular}{|l|l|}
\hline \multicolumn{1}{|c|}{ Parameter } & \multicolumn{1}{c|}{ Value } \\
\hline \hline Prandtl Number $(\operatorname{Pr})$ & 0.71 \\
Bulk Total Enthalpy $\left(h_{0}\right)$ & $4700 \mathrm{BTU} / \mathrm{lbm}\left(1.1 \times 10^{7} \mathrm{~J} / \mathrm{kg}\right)$ \\
Radius of Curvature $\left(R_{c}\right)$ & 1 in. $(2.54 \mathrm{~cm})$ \\
\hline
\end{tabular}

were assumed to apply. The heating rate was determined using the convection equation modified to use specific enthalpy instead of temperature as shown in Equation 2, repeated here as

$$
q^{\prime \prime}=\frac{\bar{h}}{c_{p}}\left(i_{w}-i_{a w}\right) .
$$

The adiabatic wall enthalpy was estimated using the recovery factor,

$$
r=\frac{i_{a w}-i_{\infty}}{i_{0 e}-i_{\infty}}
$$

which, under laminar flow assumptions, was estimated by

$$
r=\operatorname{Pr}^{1 / 2} \text {. }
$$

The average convective heat transfer coefficient was determined through a series of correlations with known flow parameters. First, the heat transfer coefficient was determined from the averaged Nusselt number by

$$
\overline{\mathrm{Nu}}_{L}=\frac{\bar{h} L}{k} .
$$

A simple integration shows that, because the plate was assumed to be heated along its entire length,

$$
\overline{\mathrm{Nu}}_{L}=2 \mathrm{Nu}_{x=L} .
$$


Thus, the averaged heat transfer coefficient for the entire plate was calculated by determining the local Nusselt number for the plate at point $x=L$. The Nusselt number was defined in terms of the Reynolds and Prandtl numbers as

$$
\mathrm{Nu}_{x}=0.332 \operatorname{Pr}^{1 / 3} \operatorname{Re}_{x}^{1 / 2} .
$$

\section{Gas Chemistry Considerations}

During arc jet testing, a gas mixture approximating that of atmospheric air $\left(\sim 80 \% \mathrm{~N}_{2}, \sim 20 \% \mathrm{O}_{2}\right)$ is injected into the arc jet tunnel, where the gas molecules are dissociated by the heater electrical arc. The dissociated gas approaches a chemical and thermodynamic equilibrium different than that of atmospheric air. For the approximate side wall heating analysis presented in this study, the chemical mixture determined by JSC's Nonlinear Arc-Tunnel Analysis (NATA) code was sufficient to generate a reasonable heating estimate. This was a sufficient estimate because the heating predictions were based on enthalpy transfer, which included gas chemistry. The major chemical components of the gas mixture are shown in Table 10. Other chemical components had mole fractions several orders of magnitude less than the species shown and were not considered in the analysis.

\begin{tabular}{|c|c|}
\hline Species & Mole Fraction \\
\hline \hline $\mathrm{N}$ & 0.339 \\
$\mathrm{~N}_{2}$ & 0.371 \\
$\mathrm{O}$ & 0.290 \\
\hline
\end{tabular}

Table 10. Mole fractions of arc jet gas species located at jet nozzle exit plane

The properties of the gas mixture were assumed to be molar-weighted sums of the properties of the individual gas species. A generic gas mixture property $X$ was determined from the individual gas species property $X_{n}$ by

$$
X=\sum_{n=1}^{N} X_{n} \eta_{n} .
$$

The properties of the gas species were estimated by using principles of statistical thermodynamics. Based on Table 10, the gases in the vicinity of the test fixture were either monatomic or diatomic. A monatomic gas has three translational thermal degrees of freedom, each of which contributes $\frac{1}{2} R$ to the constant volume specific heat, $c_{v}$. In this case, $R$ is the specific gas constant for the species in question and is equal to

$$
R_{n}=\frac{\Re}{\mathrm{MW}_{n}} .
$$

This is assumed true for any temperature between roughly $1 \mathrm{~K}$ and $9000 \mathrm{~K}$, so that electrical thermal degrees of freedom do not play a role. ${ }^{10}$ Diatomic molecules have several more thermal degrees of freedom than monatomic gases. In addition to the three translational degrees, diatomic molecules possess two rotational degrees of freedom which are fully excited for temperatures above approximately $3 \mathrm{~K}$. Furthermore, two vibrational thermal degrees of freedom also exist for diatomic molecules. The vibrational modes begin to excite at roughly $600 \mathrm{~K}$ and are fully excited for temperatures above $2000 \mathrm{~K}$.

While temperatures behind the shock wave were anticipated to be greater than $2000 \mathrm{~K}$, the boundary layer temperature (quantified by the Eckert reference temperature, shown later in Equation 18) was within the vibrational excitation temperature range. The constant volume specific heat of a diatomic gas was expected to be between $\frac{5}{2} R$ and $\frac{7}{2} R$.

Sample calculations were made for cases with and without accounting for the diatomic vibrational energy modes. Due to a complex interaction of parameters, higher heat transfer rates were found for the cases with excited vibrational energy modes. The increased specific heat of the gas lowered the boundary layer temperature and increased the gas density. This in turn increased the Reynolds number, ultimately increasing the value of $\bar{h}$. The increase in the convective heat transfer coefficient resulted in a greater heat transfer rate despite the reduced boundary layer temperature. Therefore, the constant volume specific heat of diatomic gases was assumed to have a value of $c_{v}=\frac{7}{2} R$ for a conservative heating estimate. 
With the specific heats of the individual gas species known, the temperature and gas properties behind the shock wave were determined. The gas mole fractions produced by the NATA code were initially assumed to apply to the gas behind the shock wave, and further refinements to the mixture were made iteratively. While this neglected nonequilibrium effects, it provided an estimate of the gas chemistry sufficient to give a rough prediction of the side wall heating rates. The constant pressure specific heat of the gas mixture was calculated from the constant volume specific heats of each gas species by

$$
c_{p}=\sum_{n=1}^{N}\left(c_{v_{n}}+R_{n}\right) \eta_{n} .
$$

Several of the parameters used in the determination of the Reynolds number and Prandtl number were temperature dependent. The dynamic viscosity was calculated using Sutherland's Law, shown as

$$
\mu=\mu_{0} \frac{T_{0}+S}{T^{*}+S}\left(\frac{T^{*}}{T_{0}}\right)^{3 / 2} .
$$

The thermal conductivity was also required for the determination of both the Prandtl number and the Nusselt number. Ideal gas relations were used to determine this parameter

$$
k^{*}=\frac{2}{3 \pi^{2}} \frac{\sqrt{\pi m \mathbf{k} T^{*}}}{d^{2}} c_{v} .
$$

The Eckert reference temperature was an averaged temperature in the boundary layer and allowed quantification of the gas properties at a single temperature. This simplified the heating estimate by providing an alternative to integrating temperature-dependent gas properties through the boundary layer where high thermal gradients exist. The Eckert reference temperature was defined as

$$
T^{*}=T_{\infty}+0.50\left(T_{w}-T_{\infty}\right)+0.22\left(T_{a w}-T_{\infty}\right)
$$

Temperatures were calculated from the respective enthalpies by

$$
T_{x}=i_{x} / c_{p_{x}}
$$

where $\mathrm{x}$ is a generic subscript.

By using the procedure listed above, the heating calculation for a single side wall was $11 \mathrm{BTU} / \mathrm{s} \cdot \mathrm{ft}^{2}\left(130 \mathrm{~kW} / \mathrm{m}^{2}\right)$. The gas chemistry throughout the flow was assumed to be equal to that output by the NATA code and was not corrected for temperature. However, nonequilibrium effects and chemical recombination in the boundary layer increased the gas $c_{p}$, which increased $\bar{h}$ and therefore the heat transfer rate.

\section{References}

${ }^{1}$ Dunlap, Jr., P. H., Steinetz, B. M., and DeMange, J. J., “Advanced Seal Development at NASA GRC for Future Space Vehicles,” NASA/TM2003-212478, June 2003.

${ }^{2}$ Dunlap, Jr., P. H., Steinetz, B. M., Curry, D. M., DeMange, J. J., Rivers, H. K., and Hsu, S.-Y., "Investigations of a Control Surface Seal for Re-Entry Vehicles," AIAA Journal of Spacecraft and Rockets, Vol. 40, No. 4, Aug. 2003, pp. 570-583.

${ }^{3}$ Dunlap, Jr., P. H., Steinetz, B. M., Curry, D. M., Newquist, C. W., and Verzemnieks, J., "Further Investigations of Control Surface Seals for the X-38 Re-Entry Vehicle," NASA/TM-2001-210980, July 2001.

${ }^{4}$ Taylor, S. C., Dunlap, Jr., P. H., Steinetz, B. M., and DeMange, J. J., "Evaluation and Modeling of High Temperature Knitted Spring Tubes for Structural Seal Applications," 40th AIAA/ASME/SAE/ASEE Joint Propulsion Conference, No. AIAA-2004-3890, NASA TM/, July 2004.

${ }^{5}$ Dunlap, Jr., P. H., Steinetz, B. M., and DeMange, J. J., "High Temperature Propulsion System Structural Seals for Future Space Launch Vehicles," NASA/TM-2004-212907, Jan. 2004.

${ }^{6}$ Newquist, C. W., Verzemnieks, J., Keller, P. C., Rorabaugh, M., and Shorey, M. W., “Advanced High Temperature Structural Seals," NASA/CR-2002-211973, Oct. 2002.

${ }^{7}$ DeMange, J. J., Dunlap, Jr., P. H., and Steinetz, B. M., “Advanced Control Surface Seal Development for Future Space Vehicles,” NASA/TM2004-212898, Jan. 2004

${ }^{8}$ Holman, J. P., Heat Transfer, McGraw-Hill Book Company, 5th ed., 1981.

${ }^{9}$ Lattime, S. B., Steinetz, B. M., and Robbie, M. G., "Test Rig for Evaluating Active Turbine Blade Tip Clearance Control Concepts," NASA/TM-2003-212533, July 2003.

${ }^{10}$ John D. Anderson, J., Hypersonic and High Temperature Gas Dynamics, American Institute of Aeronautics and Astronautics, 2000. 


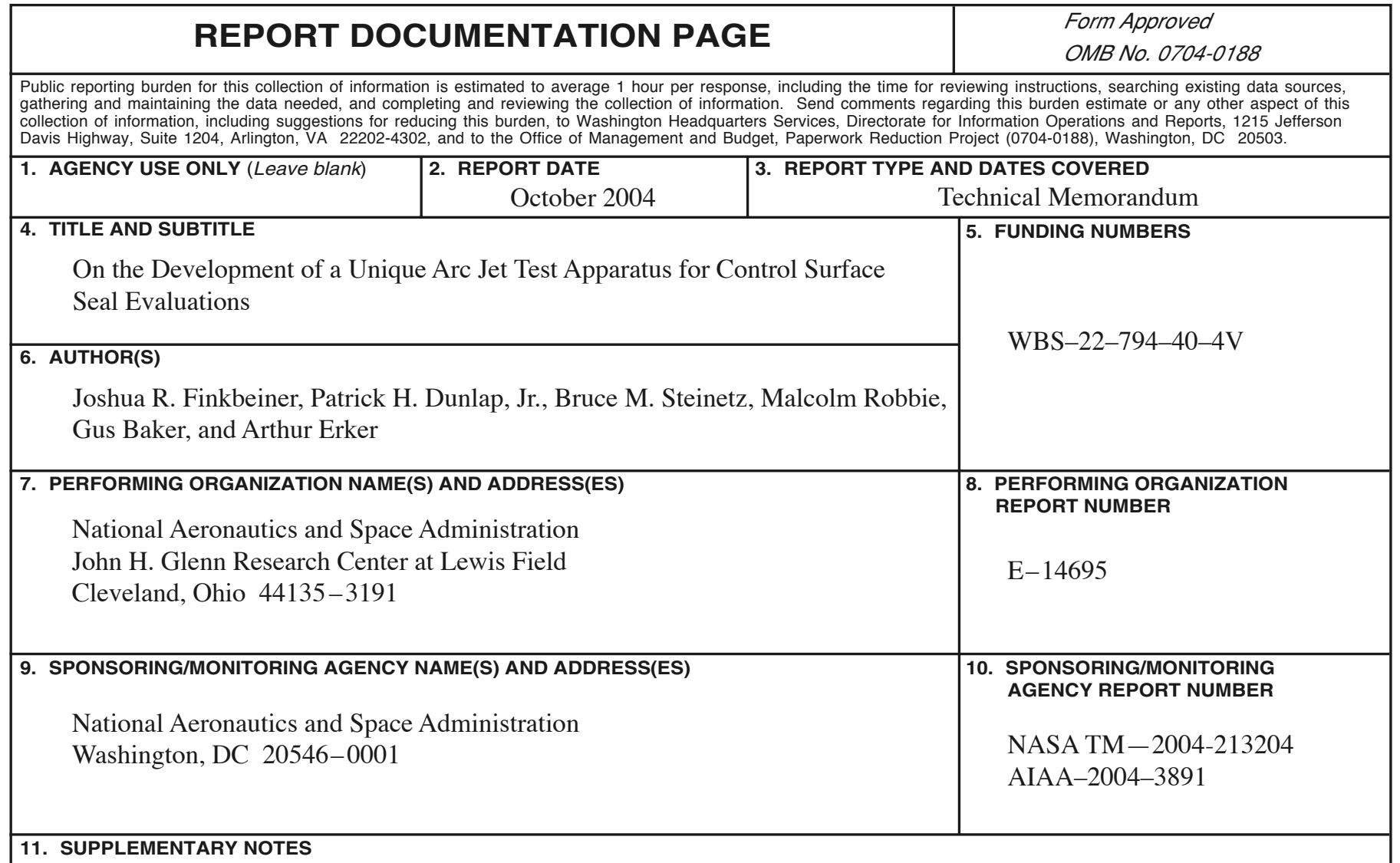

Prepared for the 40th Joint Propulsion Conference and Exhibit cosponsored by the AIAA, ASME, SAE, and ASEE, Fort Lauderdale, Florida, July 11-14, 2004. Joshua R. Finkbeiner, Patrick H. Dunlap, and Bruce M. Steinetz, NASA Glenn Research Center; and Malcolm Robbie, Gus Baker, and Arthur Erker, Analex Corporation, Brook Park, Ohio 44142. Responsible person, Joshua R. Finkbeiner, organization code 5950, 216-433-6080.

12a. DISTRIBUTION/AVAILABILITY STATEMENT

12b. DISTRIBUTION CODE

Unclassified - Unlimited

Subject Category: 37

Distribution: Nonstandard

Available electronically at http://gltrs.grc.nasa.gov

This publication is available from the NASA Center for AeroSpace Information, 301-621-0390.

\section{ABSTRACT (Maximum 200 words)}

NASA Glenn has developed a unique test apparatus capable of evaluating control surface seal and flap designs under simulated reentry heating conditions in NASA Johnson's arc jet test facility. The test apparatus is capable of testing a variety of seal designs with a variety of control surface materials and designs using modular components. The flap angle can be varied during testing, allowing modification of the seal environment while testing is in progress. The flap angle is varied using an innovative transmission system which limits heat transfer from the hot flap structure to the motor, all while keeping the components properly aligned regardless of thermal expansion. A combination of active and passive cooling is employed to prevent thermal damage to the test fixture while still obtaining the target seal temperature.

\begin{tabular}{|c|c|c|}
\hline \multicolumn{3}{|c|}{$\begin{array}{l}\text { 14. SUBJECT TERMS } \\
\text { Sealing; Spacecraft structures; Leakage reduction; Hypersonic heat transfer; Hypersonic } \\
\text { test apparatus; Arc chambers }\end{array}$} \\
\hline $\begin{array}{l}\text { 17. SECURITY CLASSIFICATION } \\
\text { OF REPORT }\end{array}$ & $\begin{array}{l}\text { 18. SECURITY CLASSIFICATION } \\
\text { OF THIS PAGE }\end{array}$ & $\begin{array}{l}\text { 19. SECURITY CLASSIFICATION } \\
\text { OF ABSTRACT }\end{array}$ \\
\hline Unclassified & Unclassified & Unclassified \\
\hline
\end{tabular}



